Getting a Feel for Tactile Space:

Exploring Haptic Perception of Microtexture Martin Arvidsson 



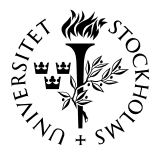

Stockholm

University

\title{
Getting a Feel for Tactile Space: Exploring Haptic Perception of Microtexture
}

\author{
Martin Arvidsson
}

C Martin Arvidsson, Stockholm 2012

ISBN 978-91-7447-608-8

Printed in Sweden by US-AB, Stockholm 2012

Distributor: Department of Psychology, Stockholm University 

To Ebba and Paula 



\section{Abstract}

The present thesis is based on three studies that research different aspects of fine texture perception. The goal is to better understand the mechanisms involved in haptic perception of textures below $200 \mu \mathrm{m}$, also known as microtextures. Study I was conducted to establish a friction measurement model and relating the friction measurements to perceived coarseness of fine textures. A set of printing papers was used as stimulus material. In Study II an expanded set, including the set of Study I, was used as stimuli in a multidimensional scaling (MDS) experiment of haptic fine texture perception. Through scaling of perceptual attributes and similarities, a three dimensional space was found to best describe the data and the dimensions were interpreted as rough-smooth, thick-thin and distinct-indistinct. In Study III a series of model surfaces were manufactured with a systematically varied sinusoidal pattern, spanning from $300 \mathrm{~nm}$ to $80 \mu \mathrm{m}$. As in Study II, a similarity experiment was conducted and a two dimensional space was chosen, the dimensions of which were explained well through friction and the wavelength. Together these three studies form a better picture of fine texture perception. The dimensionality found with paper stimuli was very similar to the corresponding spaces for marcrotextures of everyday materials, even though a different perceptual system is used for fine texture perception. Regardless if the information is coded through the spatial or the vibratory sense, the perception does not seem to differ in dimensionality. Further, the largest among the microtextures seem to have been perceived as carrying spatial information. On the systematically varied, rigid, textures, the MDS space did not come out in a similar fashion to those of everyday materials but instead similar to the physical properties that characterizes the change in the textures. It was further found that the participants in Study III successfully discriminated textures with an amplitude of $13 \mathrm{~nm}$ from the unwrinkled surfaces. From these studies the main conclusions are (a) haptically measured friction and surface roughness are important contributors to fine texture perception, (b) even at microscales, spatial information is retrieved haptically, probably through vibrations, and (c) persons can haptically discriminate textures at a nanoscale.

Key words: Haptic, fine texture perception, multidimensional scaling, tactile, roughness, vibrations, spatial 


\section{Acknowledgements}

First I would like to thank my supervisor, Professor Birgitta Berglund, who believed in me from the start, and shared her vast knowledge of perception psychology and psychophysics. I have never met a person more enthusiastic and devoted to science, it's been a pleasure working with you throughout my years as a PhD student. My co-supervisor Associate Professor Mats Nilsson for invaluable insight on methodology and multivariate statistics, as well as being one of the nicest and most helpful individuals I ever worked with. Associate Professor Fredrik Jönsson and Professor Steven Nordin for taking their time to review this thesis and helping me improve it.

During my $\mathrm{PhD}$ studies I have worked closely with several wonderful people at KTH and YKI, and it's been a great experience. Thank you all. I would especially like to thank Lisa Skedung ( $\mathrm{PhD}$ by the time this is printed), and Professor Mark Rutland. It has not only been great working with both of you, but also fun to be around you. I hope there will be more collaboration in the future.

Anna Lindqvist and Stina Cornell Kärnekull who both had the misfortune to get stuck in the same office as me, if the goddesses are good you'll be more fortunate in 2013 !

My fellow PhD students (in no particular order, other than order of popularity) Artin Arshamian, Margareta Hedner, Jesper Alvarsson, Maria RådstenEkman, Henrik Nordström, Elmeri Syrjänen, Cathrine Sundling, Veit Kubik, Jelena Corovic, Lena Låstad, Anders Sand, Kristina Karlsson, Gustaf Törngren, Armita Golkar as well as my friends and colleagues who beat me to the finish line, Drs. Håkan Andersson, Johanna Lovén, Nathalie Peira, Neda Kerimi, Östen Axelsson, Li Zheng, Anne Richter, and Emma Bäck. Thank you all for discussions, venting, beer drinking and general good times.

A warm thank you to my mother Anita Arvidsson and my fathers Torsten Arvidsson and Artur Forsberg for help and support throughout my life, allowing me to grow up in an encouraging environment as well as having faith in my abilities (save for my ability to play the piano). I would also like to thank my sister Katarina Vybacke who did have a talent for playing the piano and thus distracted the attention of aforementioned persons. 
The Rudgard family, for opening their arms and making me feel welcomed in and, a part of, their family. Thank you!

My friends outside of academia thank you for reminding me of the world outside of microtexture and review processes. Special thanks to Robert Glad, Jonas Larsson, Carl Magnus Weckfelt and Andreas Attorps.

And finally a big thank you to the most important individuals in my life, Paula Rudgard and Ebba Arvidsson, I love you both.

Everyone that I may have forgotten, ignored out of spite, or in other ways slandered, thank you for reading the acknowledgments!

The research was conducted within the Institute Excellence Center CODIRECT (Controlled Release and Delivery Center) funded by Vinnova, The Knowledge Foundation and Industry (initially also by the Swedish Foundation for Strategic Research). I would also like to express my gratitude to Stockholm University and the Department of Psychology for the position as a PhD student. 


\section{List of studies}

The present Doctoral thesis is based on the following three studies:

Study I Skedung, L., Danerlöv, K., Olofsson, U., Johannesson, C. M., Aikala, M., Kettle, J., Arvidsson, M., Berglund, B., \& Rutland, M. W. (2011). Tactile perception: finger friction, surface roughness and perceived coarseness. Tribology International. 44. 505-512.*

Study II Arvidsson, M., Skedung, L., Aikala, M., Danerlöv, K., Kettle, J., Rutland, M. W., \& Berglund, B. (2012). Haptic perception of fine surface texture: psychophysical interpretation of the multidimensional space (resubmitted manuscript).

Study III Skedung, L., Arvidsson, M, Chung, J., Y., Stafford, C.,M., Berglund, B., \& Rutland, M. W. (2012). Feeling small: exploring the tactile perception limits. (submitted manuscript).

* Study I is reprinted with permission from the publisher. 


\section{Contents}

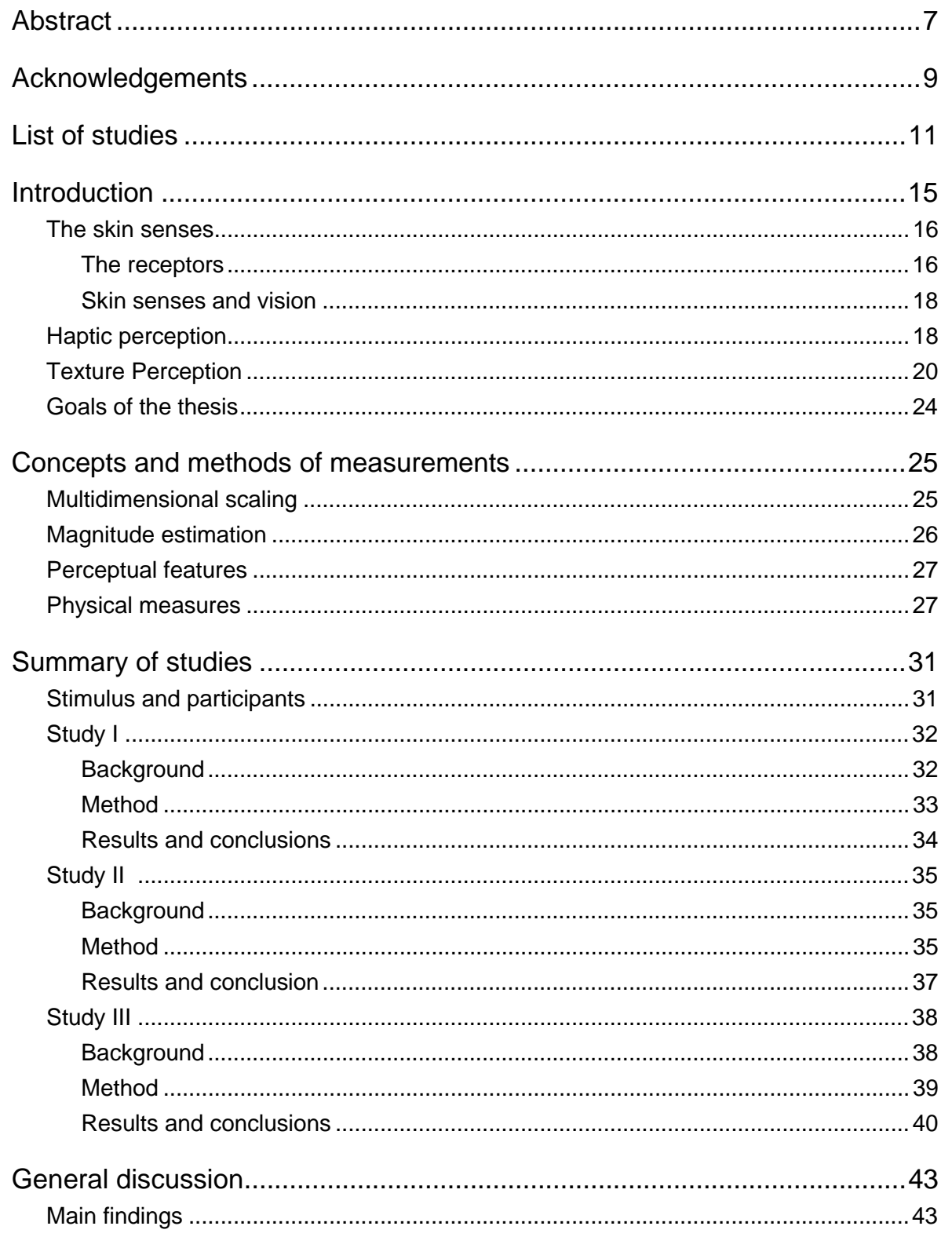




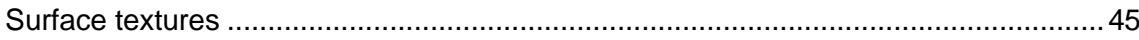

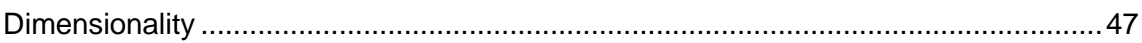

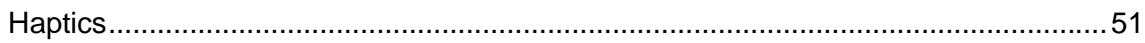

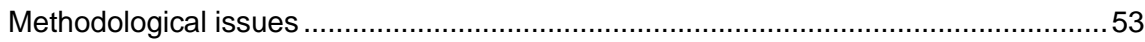

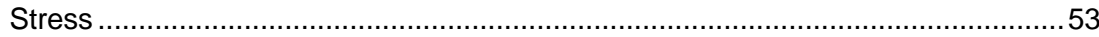

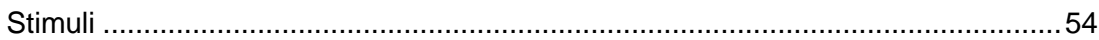

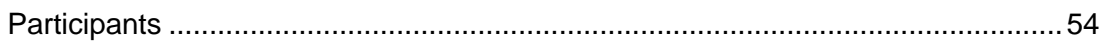

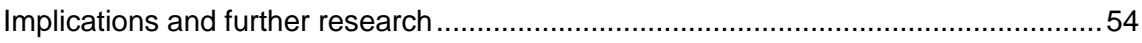

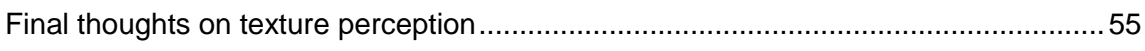

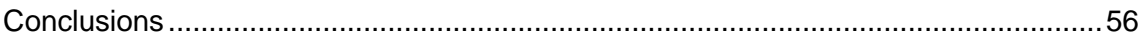

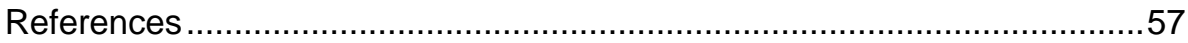




\section{Introduction}

We see with our eyes, hear with our ears, smell with our noses, and experience touch with our whole body. Touch is in many ways unique from the other senses in many ways, mainly because it is not a single sense, but rather a composition of several senses that create perceptions of pressure, vibration, warmth, cold, pain, and irritation as well as of combinations of these (e.g., Green, 1990). However, there is also a lot of sensory overlap, with vision in particular. The information we retrieve through these senses allows us not only to gather information about objects we handle and interact with, but they also play a major role in our everyday life, ranging from wanted and unwanted contact with other humans to feed-back about where our feet are so we don't just fall over. Although a classic research area that sparked interest in renowned scientists such as David Katz and Ernst Heinrich Weber (e.g. Katz, 1925; Weber, 1851), tactile perception has historically been somewhat neglected and the research interests dwarfed in the presence of the vision and auditory research. However, in more resent years research about the skin senses has received further interest, likely prompted by new potentials of technological advancements such as remote touching (e.g., remote surgery) and different forms of haptic interfaces (Grunwald, 2008).

Currently there are combined efforts from multiple fields, in researching and understanding texture perception, examples include, engineering (Childs \& Henson, 2007), tribology (Derler \& Gerhardt, 2012), and psychology (Hollins \& Bensmaïa, 2007). The importance of understanding texture perception span from economical interests, such as consumer preferences of papers and textiles, to developing robotic prosthetic limbs and virtual reality immersion.

The goals of this thesis is to further the knowledge of haptic perception of microtexture. In three experimental studies, multidimensioal scaling (MDS), and magnitude estimation are used to examine the perception of simple and complex patterns of microtexture, to examine the contribution of friction and roughness and to examine the roles of vibratory and spatial senses in microtexture perception, finally, to research if nano-scale textures can influence haptic perception. 


\section{The skin senses}

The skin senses are used to retrieve a large variety of information spanning from more affective interpersonal touch and general positioning of the body to object identification and texture perception (Lederman \& Klatzky, 2009). The sense of touch is actually a whole sensory system, or rather two separate subsystems made up by mechanoreceptors as well as thermal and pain receptors. These are the cutaneous and the kinesthetic systems (Lederman \& Klatzky, 2009), both of these convey spatial, vibratory, cold, warmth, and pain information. Since the focus of this thesis is on texture perception, the mechanoreceptors in glabrous (hairless, e.g. the fingertips) skin are of specific interest. These mechanoreceptors can in turn be divided into fast and slow adapting receptors; Table 1 shows the different types of receptors and their optimal sensitivity.

Table 1. Mecanoreceptors in glabrous skin, classification and functionality.

\begin{tabular}{llll}
\hline Receptor & Adaptation speed & Haptic & Texture \\
\hline Merkel & Slow (SA1) & Passive & Coarse \\
Meissner & Rapid (RA1) & Active & Fine \\
Ruffini & Slow (SA2) & Passive & Coarse \\
Pacinian & Rapid (RA2) & Active & Fine \\
\hline
\end{tabular}

\section{The receptors}

The relevant receptors for the skin senses are the mechanoreceptors, thermal receptors and nociceptors. The four major types of mechanoreceptors that convey tactile information are Meissner, Merkel, Ruffini and Pacinian. The following section will briefly cover the basics of these receptor types. For a more detailed description of these receptors, their physiology and their role in tactile perception, see Grunwald (2008). The Mechanoreceptors are distributed in the skin throughout the body, but at varying densities. The hand, for example, which is the primary area of interest for this thesis, has around 17000 mechanoreceptors (Vallbo \& Johansson, 1984).

Meissner corpuscles are found in the papillary layer of the dermis. These mechanoreceptors mainly respond to small indentations of the skin (10's of microns). The optimal frequency for these receptors is below $50 \mathrm{~Hz}$ (Johansson, Landström \& Lundström, 1982). For scale, it can be noted that the corpuscles are about $40-70 \mu \mathrm{m}$ wide and their axons are around $5 \mu \mathrm{m}$. This is a rapidly adapting receptor. 
Merkel cells are also found in the epithelial tissue of the skin. These mechanoreceptors are slow adapting and respond to lasting indentations of the skin. There is some controversy regarding the functionality of these cells (Halata, Grim, \& Baumann, 2003)

Ruffini corpuscles are found both in the dermis and in the joints. These mechanoreceptors monitor the stretching of skin and joints, and are, thusly, relevant for the cuntaneous and the kinesthetic systems. They are slow adapting receptors.

Pacinian corpuscles are like the Ruffini corpuscles found in the joints and in the skin. However, unlike the Ruffini corpuscles these receptors are not located in the dermis, but rather in the subcutaneous tissue. The Pacinian corpuscles respond to vibrations but unlike the Meissner cells that are optimal around $50 \mathrm{~Hz}$ the Pacinian corpuscles have their optimal sensitivity around $200 \mathrm{~Hz}$ (Johansson et al., 1982; Brisben, Hsiao, \& Johnson, 1999).

Thermal receptors respond in the range of $5-45^{\circ} \mathrm{C}$ and the normal skin temperature is between $25-36{ }^{\circ} \mathrm{C}$ (Verrillo, Bolanowski, Checkosky, \& McGlone, 1998). Since objects and surfaces are usually, but not always, cooler than the normal skin temperature, heat is conducted out of the skin (Ho \& Jones, 2004). Bergmann Tiest and Kappers (2009) showed that humans can actually discriminate materials, to some extent, based on thermal properties alone. The remaining receptor group, akin to thermal receptors, is the nociceptors that respond to pain, for example, temperatures below $5{ }^{\circ} \mathrm{C}$ and above $45^{\circ} \mathrm{C}$.

The cutaneous system is basically the part of our body that is in direct contact with the stimuli. It consists of both mechano- and thermoreceptors in the epidermis (the outermost layer of skin), the dermis (the thick middle part of the skin) and the subcutaneous tissue (the deepest layer of skin). This is naturally the most important system for haptic object and texture perception. There is a plethora of research done on the cutaneous system, ranging from illusions to neurological studies, density of receptors and receptor functionality (see Grunwald, 2008).

The kinesthetic system: Is made up by mechanoreceptors, Ruffini/Pacinian, and nociceptors in the muscles, tendons, and joints (Gandevia, 1996; Grunwald, 2008). The primary functions of the kinesthetic system are to provide information about force and location in space. For example, if you want to pick up and drink from a cup of coffee you will have to have information about the weight of the cup to assess the force needed to hold it, you then need information to track and balance the cup during its travel from the table to your mouth without spilling, all this sensory information is retrieved 
through the kinesthetic system. Even though the kinesthetic system may seem more relevant to the larger scope of tactile perception, it is also important when considering texture perception. Lederman and Klatzky (2004) determined the perceptual costs of limiting haptic exploration. Participants were asked to identify objects, while blind folded. Several restrictions were imposed on participants, including a plastic sheath over the fingers and splintering the fingers to restrict movement. Such restrictions gave significantly poorer performance in the restricted than the free condition. The splinting of the fingers condition highlighted the need for kinesthetic information in touch.

\section{Skin senses and vision}

As previously mentioned, vision has dominated perception research for a long time and though vision may seem different from the skin senses they share some characteristics. The greatest similarity for these two senses is the identification of objects and texture. While vision is a lot faster (not necessarily better) at identifying objects (Klatzky, Lederman, \& Metzger, 1985), the skin senses are better at analysing surface properties (Lederman \& Klatzky, 2009, Guest \& Spence, 2003). The temporal resolution for tactile perception is even better than that of vision; for example, Gescheider (1974) found that participants could distinguish repeated tactile stimuli down to 5 msec. While vision can get you an idea of the weight of an object, the eye can be fooled and you will get a better estimate by actually picking up the object; the same is true for estimates of warmth or cold as well as assessment of textures. These senses also share a lot of psychological phenomena. For example, many visual illusions are transferable to the sense of touch, for example the cutaneous rabbit, where two pokes at different spots of a body part, in rapid succession, will be perceived as the poke "wandering" along a line between the two stimulated areas, i.e. movement. This phenomenon is identical to the visual illusion where two flashing dots on a screen will produce the illusion of a dot wandering across the screen (Geldard, \& Sherrick, 1972; Goldreich, 2007; Miyazaki, Hirashima \& Nozaki, 2010). Given the sensory overlap between these two senses, it is important it is to eliminate vision from the experimental context when studying the skin senses.

\section{Haptic perception}

There are two distinct different forms of touch active and passive (for further divisions see Bolanowski, Verrillo \& McGlone, 2004). Active (haptic) touch differs from passive touch both by the exploratory procedure and physiologically. Most of the research on tactile perception has focused on passive touch, in which participants passively receives a stimulus exposure. Active, 
or haptic, touch is when a person actively searches for information, in most cases with his/her hand. There is of course active explorations with other parts of the body, for example the oral area, ask any infant. When a person engages in haptic touch the objective is to retrieve information on what is being explored. A lot of the pioneering research on haptic perception was conducted by Susan Lederman and Roberta Klatzky. For example, Lederman and Klatzky (1987) observed and characterized a series of exploratory procedures necessary for retrieving information on the various kinds of perceptions, for example, lateral motion for texture perception and pressure for hardness perception. These exploratory procedures came naturally to the participants of the study; it does seem that we intuitively all do the same exploratory procedure when asked to retrieve a specific piece of information from the object. Noteworthy is that the exploratory procedures all are secondary to grabbing and lifting the object, even for exploratory procedures like static contact to retrieve temperature information.

There is also a neural basis to support the exploratory procedures. Johnson and Lamb (1981) showed that lateral movement of the hand enhances the response of the SAI receptors (e.g. Merkel cells). These are the receptors that are primarily responsible for roughness perception of macrotextures. Further, Bensmaïa and Hollins (2003) found that lateral movement gives rise to vibrations that activate the Pacinian system (RA), which is considered the main receptor system for roughness perception of microtextures (Blake, Johnson, \& Hsiao (1997).

It is clear that the haptic procedure is of great importance in retrieving information about objects. As shown by Lederman and Klatzky (1987), lateral movement is the exploratory procedure for texture perception and vibrations are necessary to perceive textures at a microscale (Hollins \& Risner, 2000); but does it matter if the vibrations are induced actively or passively, i.e. does the kinesthetic system contribute to the perception of these fine surfaces? Yoshioka, Craig, Beck and Hsiao (2011) found that perceived roughness constancy was achieved in both active and pseudo-active exploration (hand moved by the experimenter) for both direct and indirect touch (mediated with a probe), but not for passive touch. This suggests that the kinesthetic system is also, at least to some degree, involved in texture perception.

Most experiments on roughness and texture perception are conducted on small surfaces where the effect of the kinesthetic system would be limited because of the movement constraint imposed by the stimulus size. It is not as well studied how this translates to larger scanning areas where more kinesthetic information is conveyed through larger movements. Lakatos and Marks (1999) showed that local features are predominant in initial exploration, but if permitting prolonged exploration of the surfaces, global features 
will then become more important. Even though there is some debate regarding the importance of active exploration in texture perception, there is no debate regarding the necessity of haptic exploration to evoke the whole perceptual system, and not just the cutaneous system (Yoshida, 1968; see further Lederman \& Klatzky, 2009).

\section{Texture Perception}

When we scale down from haptic perception of objects, for example size, shape, weight, and object identification, we get to the surface. Is it hot, cool, rough, and smooth or are there any recognizable patterns on the surface? This surface perception involving the textures will here further be discussed and classified as fine or coarse based on the size of the elements that constitute the texture, and simple or complex depending on the arrangements of the elements on the surface.

Coarse texture, or marcrotexture, is in this thesis attributed to surfaces covered with elements with sizes larger than $200 \mu \mathrm{m}$. Textures in this range should mainly be perceived through the spatial sense (Bensmaïa \& Hollins, 2003, 2005; Blake, Hsiao \& Johnson, 2007; Merkel cells), with little contribution from the vibratory sense (Pacinian). The roughness perception for textures in this range is well studied (Lederman \& Klatzky, 2009) as is also the more complex haptic perceptions in multidimensional experiments (Bergmann Tiest \& Kappers, 2006; Gescheider, Bolanowski, Greenfield, \& Brunette, 2005; Hollins, Bensmaïa, Karlof, \& Young, 2000; Yoshioka, Craig, Beck, \& Hsiao, 2007). The dimensionality of coarse structures is usually described as three dimensional, explained through RoughnessSmoothness, Hardness-Softness and Slippery-Sticky (Bergmann Tiest \& Kappers, 2006; Hollins, Bensmaïa, Karlof, \& Young, 2000; Picard, Dacremont, Valentin, \& Giboreau, 2003). There is also strong indication that the third dimension could arise from stimulus identification (Hollins, Bensmaïa, Karlof, \& Young, 2000).

Fine texture, or microtexture, is in this thesis defined as surfaces covered with elements with sizes smaller than $100 \mu \mathrm{m}$. Textures in this size range is believed to be perceived mainly through the fast adapting (FA) vibratory sense (Pacinian) with little contribution from the slow adapting (SA) spatial sense (Bensmaïa \& Hollins, 2005; Meissner). Although fine textures are not as well investigated as coarse textures, but all the same there have been considerable research efforts made mainly on roughness (e.g. Hollins, \& Bensmaïa, 2007; Taylor \& Lederman, 1975; Libouton, Barbier, Berger, Plaghki $\&$ Thonnard, 2012) and thresholds (e.g. Johansson et al., 1982). While there have been considerable research on fine textures, there has been no multidi- 
mensional experiments on textures with element sizes below $200 \mu \mathrm{m}$, that this author is aware of.

Complex texture is in this thesis defined as textures manufactured for a specific use, and not specifically to be researchable in a systematic way according to 'rigid' element sizes. Such textures are well researched on coarse, or macro-element, textures (e.g. Bergmann Tiest \& Kappers, 2006; Picard, Dacremont, Valentin, Giboreau, 2003), but little research has been conducted on fine textures; and as far as the author knows, no multidimensional research has been done exclusively on these kinds of textures. For an example of fine, complex surfaces, Figure 1 shows a profile scan of three of the finetexture papers used in Study II in this thesis.

Simple texture is in this thesis regarded as textures manufactured to vary systematically in a given physical property, all other properties held constant. An illustration of a simple texture from Study III is shown in Figure 2. Such surfaces and textures have attracted a lot of attention, especially regarding roughness perception of coarse textures, for example, Gescheider, Bolanowski, Greenfield, \& Brunette (2005). The benefit of these textures of course is that isolated properties can be researched, but how well do these surfaces generalize to perceptions that arise from more complex textures? A systematic variation of surface elements will affect the perceived roughness, but complex textures provide a greater context and will likely affect more than just the roughness perception.

Regarding texture perception, the far most researched aspect is the perception of 'roughness'. Taylor and Lederman (1975) found that for roughness perception the spatial distribution or organaization was superordinate to the size of the texture elements, i.e. the roughness was mainly explained by the width of the grooves, not the width of the peaks. It was further demonstrated that friction was of little importance to the perception of textures (Lederman, 1974). This however, was only true in the case of large textures but not for finer textures.

The idea of separate perceptual systems for fine and coarse textures traces back to David Katz (Katz, 1925/1989). His idea was that for coarser textures, a spatial sense is used for discrimination, and for fine textures, we rely on a vibratory sense. This theory is called the Duplex Theory of roughness perception. Katz's theory evoked some interest in more resent years and got support through (Gescheider 1976; Gescheider, Verrillo, Capraro \& Hamer, 1977; Hollins \& Risner, 2000). Hollins and Risner also established a limit at a texture element size of $200 \mu \mathrm{m}$ that separate the spatial and vibratory senses. Below $200 \mu \mathrm{m}$ there was very little contribution from the spatial sense, 
and above $200 \mu \mathrm{m}$, there was very little contribution from the vibratory sense.

There is convincing support for the theory that the vibratory sense is of little importance for the roughness perception of larger textures (e.g. Lederman, 1974; Hollins \& Bensmaïa, 2007). This also makes sense intuitively, if the texture is large enough to be perceived by just grabbing the object, stroking it, and thus inducing vibrations, will not add much to the roughness perception. The roughness perception of microtexture, on the other hand, is not as intuitive. It is known that vibrations are necessary for perceiving these textures (e.g Hollins \& Risner, 2000), but is the vibratory sense alone responsible for conveying texture information? It has been shown that probes (vibration by default) can convey spatial information through vibrations (Klatzky \& Lederman, 1999; Yoshioka et al, 2007) and in a recent study Delhaye, Hayward, Lefevre \& Thonnard (2012) showed that spatial coding was possible solely through vibrations by conveying vibrations through the hand to the forearm. Though it is well established that the vibratory system is a primary, and necessary, system for sensing fine texture (e.g. Bensmaïa \& Hollins, 2005; Gescheider, Verrillo, Capraro, \& Hamer, 1977; Gescheider, Sklar, Van Doren, \& Verrillo, 1985) it is not certain to what degree spatial information is relevant.

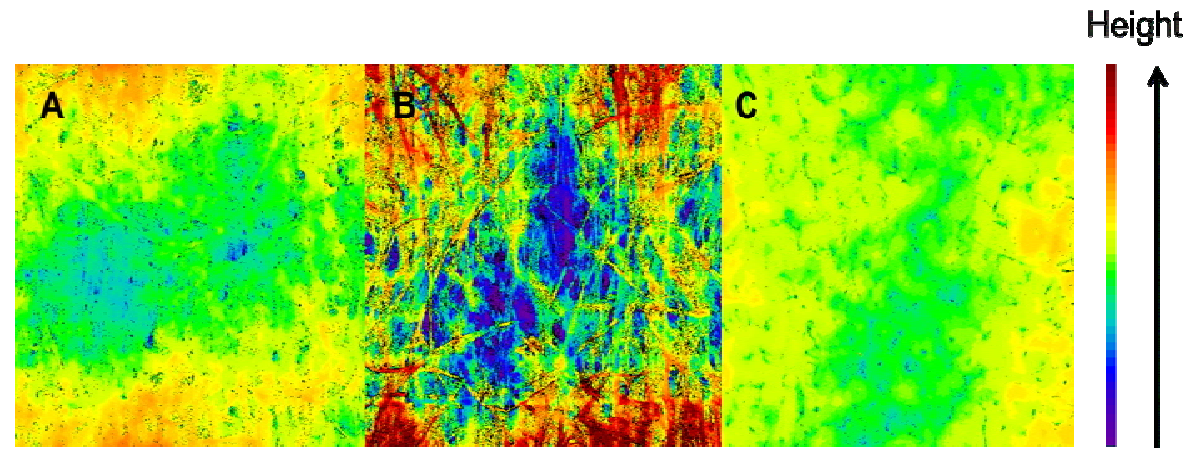

Figure 1. Three printing-paper stimuli depicting the range of surface roughness $\left(\mathbf{R}_{\mathbf{a}}\right)$ in 3D-height maps. Stimulus A: LWC 60, medium rough, $R_{a}=1.75 \mu \mathrm{m}$; Stimulus B: News 45, most rough, $R a=4.03 \mu \mathrm{m}$; and Stimulus C: WFC-Gloss 100, least rough, $R_{a}=1.24 \mu \mathrm{m}$. The 3D-area height maps $\left(2.7 \times 2.6 \mathrm{~mm}^{2}\right)$ were obtained with a profilometer based on white-light interferometry. The image of each printing-paper stimulus consists of 42 smaller images stitched together. 
The roughness researchers have also tried to determine thresholds for haptic perception, that is how small surface features that the human finger can detect. Current research holds that the human hand is capable of discriminating down to element sizes of $1 \mu \mathrm{m}$ (Johansson \& LaMotte, 1983; Miyaoka, Mano, \& Ohka, 1999; Louw, Kappers, \& Koenderink, 2000; Srinivasan, Whitehouse, \& LaMotte, 1991).

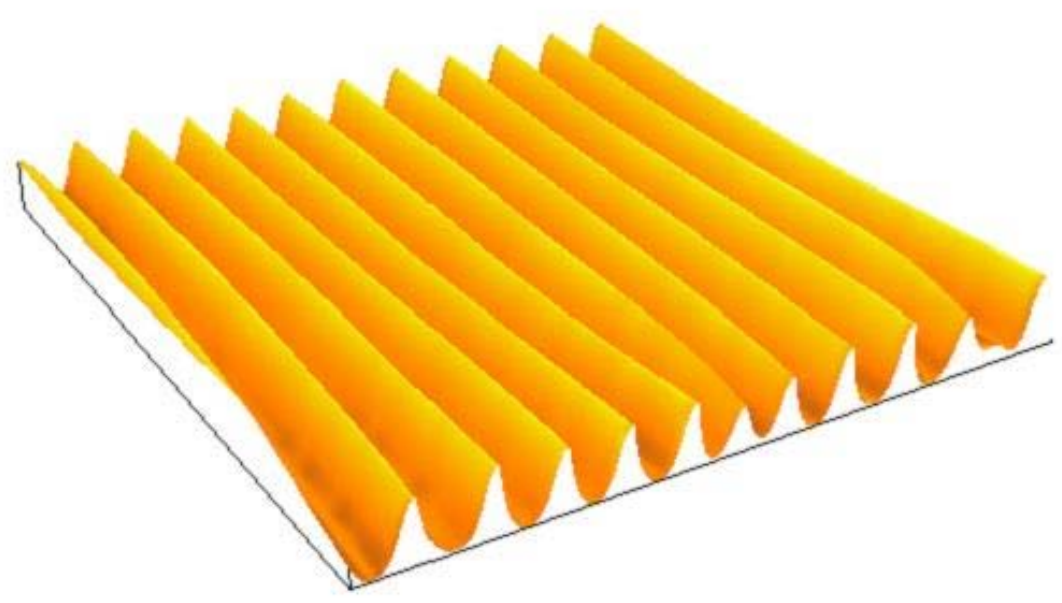

Figure 2. Visualization of the profile of one of the simple texture 'rigid' model surfaces.

In the literature on aging and texture perception, it is obvious that our tactile abilities are not spared the tooth of time. The spatial acuity, the ability to detect two pokes at a close distance on the body, declines with age for both blind and seeing persons. The decline in spatial acuity is about $1 \%$ per year between 12 and 85 years old (J.C Stevens \& Patterson, 1995). The decline is true for both blind and seeing, but blind persons perform on average at the level of 23 years younger sighted persons (Goldreich \& Kanics, 2003). It is not only the spatial sense that declines with advancing age, but also the vibratory sense. Gescheider, Edwards, Lackner, Bolanowski, and Verrillo (1996) found that the detection threshold for $250 \mathrm{~Hz}$ vibrations gets elevated with age. However, above threshold, the ability to discriminate vibration stimuli was relatively unaffected by age.

Spatial discrimination and vibrations are undoubtedly the two most important parts of haptic texture perception; they are however not acting independently of the warmth and cold senses (Bergmann Tiest \& Kappers, 2009). Given our ability to discriminate changes in temperature (Ho \& Jones, 2006), it is reasonable to assume that the thermal conductivity of the 
materials would contribute to the perception even of exclusively fine texture. For example, materials with high thermal conductivity would lead heat away from the hand quickly and feel cool.

\section{Goals of the thesis}

The goal of this thesis is to further the knowledge on haptic fine-texture perception and specifically to answer the following questions:

(a) What is the contribution of friction and surface roughness to the haptic perception of fine-textures?

(b) Can fine-textures as small as $2 \mu \mathrm{m}$ be mapped multidimensionally, and how does the dimensionality of these fine textures relate to coarse textures and objects?

(c) What is the role of texture size in the use of vibratory and spatial sense?

(d) Can the contribution of specific properties for haptic perception of finetextures be isolated?

(e) Can nano-features be distinguished with haptic perception? 


\section{Concepts and methods of measurements}

The following section will present the main methods of measurement used in the three studies, and the unidimensional features and properties that were chosen for the experiments.

\section{Multidimensional scaling}

The main method for Study II and Study III was multidimensional scaling (MDS). This is a nifty method to explore the underlying dimensionality of perceptions, as well as getting fairly unbiased data. Rather than having the experimenter decide what the participants are supposed to perceive, the participants are allowed to scale similarity with their own criteria and it is then up to the experimenter to find out what perceptional dimensions are used. In this way the data leads the experimenter to search for the important dimensions rather than the experimenter choosing what perceptual features are important and then having the participants scale them. The idea behind multidimensional scaling is that similarity data can be represented as distances which are represented in a multidimensional space (Borg \& Groenen, 2010; Schiffman, Reynolds, \& Young, 1981; Carroll \& Chang, 1970).

In Study II and Study III, where multidimensional scaling was used, the data was collected as similarities of pairwise comparisons. The participants would scale the similarities of all possible combinations of pairs of the stimulus matrix ( $21 \times 21$ and $18 \times 18$ matrices for Study II and III, respectively). In order to reduce the strain on the participants only data from half of the matrix was collected, that is, if the pair 5-2 was presented then the pair 2-5 was not included. To check the reliability of the half matrix, a subset was selected for test-retest; the same method was used to decide this subset in both Study II and III (all pairs including the first and the last stimuli as well as all pairs next to the main diagonal were included in this subset). The data was analyzed with the ALSCAL program, using the INDSCAL algorithm. In order for the ALSCAL to accept the input, the similarities must first be converted to dissimilarities $(100-X$, where $X$ is the similarity scale value). If the data is free of error the fit would be an exact and absolute representation of the data. However, psychological measurements always include a certain degree of error. The purpose of the different MDS algorithms is to fit the 
data as well as possible, given the error in the data. Since the MDS programs are black-box like and do not show the fitting process in detail, it provides a badness-of-fit measure. This badness-of-fit measure is called Stress (Borg \& Groenen, 2010).

The ALSCAL software attempts to reduce the S-Stress rather than the raw stress. S-stress means that both the distances (in the solution) and the dissimilarities (in data matrix) are squared. A benefit with this model is that all scale values including zeroes can be differentiated. However, as a consequence, the greater distances get heavier weights. A critique against S-stress is that greater distances are assumed to have more error and that S-stress then attributes more weight to the weaker data (Borg \& Groenen, 2010). In the case of the studies in the present thesis, however, it is more likely that the smaller distances contain more error because of the inability of the participants to consistently discriminate between extremely similar microtextures. Indeed, the ALSCAL solution made more sense, in relation to the physical and the perceptual unidimensional data, than the sometimes more recommended PROXSCAL software did For more information on the majorization algorithm used by PROXSCAL, see Borg and Groenen, (2010).

Individual Difference Scaling (INDSCAL software) is a model that fits weighted individual Eucledian distances in an $n$-dimensional space. What this means is that each participant gets assigned a weight depending on his or her 'preference' for the dimensions in the space, while scaling similarities among perceptions of stimuli. The reason for doing this is to account for individual differences when creating the common space for all participants. The assumption behind this is that the individual space corresponds to the common space but each of the individuals has their own idiosyncratic 'preference' for involving a particular dimension.

\section{Magnitude estimation}

Magnitude estimation is a method to scale the intensity of a stimulus (S.S Stevens, 1957, 1975). The basic premise is that participants scale the perceived intensity or a perceptual quantity of the requested feature. This is done either in relation to a, by the experimenter, predefined standard or reference (modulus) or, alternatively, the participant is allowed to set their own frame of reference relative to the set of stimuli (no-modulus). The data is collected as ratio scaling data and the participants are asked to answer accordingly. That is, if the first stimulus is considered 50 in for example smoothness and the following stimulus is twice as smooth, it should be reported as 100. Reversely, if the second stimulus is 100 in smoothness and the third stimulus is a little less than one forth thereof, it will be reported as for 
example, 22. To get solid magnitude estimation data, it is important that each stimulus is repeated several times in random or irregular orders. No-modulus (or free) magnitude estimation was the method of choice in collecting the unidimensional perceptual features in both Study I and Study II.

\section{Perceptual features}

The perceptual features that were measured in the three research studies were coarseness, smoothness, thickness, dryness and coolness. While coarseness ${ }^{1}$ and smoothness are obvious choices because of the known importance of surface roughness (Hollins, \& Bensmaïa, 2007; Taylor \& Lederman, 1975; Libouton, Barbier, Berger, Plaghki \& Thonnard, 2012), the concepts of dryness and coolness may not be as obvious choices for perception measurements. These two were selected based on a brief pilot experiment, because they were frequently occurring descriptors of the papers from non-professional perceivers of printing papers. The final feature, thickness was meant to replace the more common attribute hardness, as it would be difficult to consider the hardness (or softness) of flat printing-papers surfaces.

\section{Physical measures}

Weight. The 21 printing papers in A4-format were already produced, measured, labeled and delivered in weights according to specifications realistic for their natural use (range: 45 up to $130 \mathrm{~g} / \mathrm{m}^{2}$, see Table 1). The weight was determined according to ISO standard 536:1995 for grammage.

Finger friction. Friction is a force that resists the motion when one object is moving over another (see Figure 3). To measure finger friction, a haptic approach was adopted. That is, a human finger was moved over the paper stimulus mounted on a three-component piezoelectric force sensor (Kistler 9251A). When subjected to a mechanical load, the sensor generates electrical charges that are converted to voltage, using a charge amplifier (Kistler 5038A3). By calibration, the output signal of the measured forces was obtained in the unit Newton $(\mathrm{N})$. The finger friction coefficient was determined as the ratio of the frictional force $\left(\mathrm{F}_{\mathrm{F}}\right)$ and loading force $(\mathrm{L})$, and was calculated from an average of four measurements per paper. The haptic procedure and the apparatus, including the direction of the forces, are shown

\footnotetext{
1 'Coarseness' is the best translation of the Swedish perceptual feature "strävhet", which is equivalent to roughness; the translation to 'coarseness' in English was chosen in order to minimize confusion with the physical quantity of surface roughness, Ra.
} 
in Figure 3. The sampling rate of the frictional force and loading force was $100 \mathrm{~Hz}$. For a more detailed description of the measurement procedure for finger friction, see Skedung et al. (2010, 2011). For a review on finger friction measurement see Derler and Gerhardt (2012).

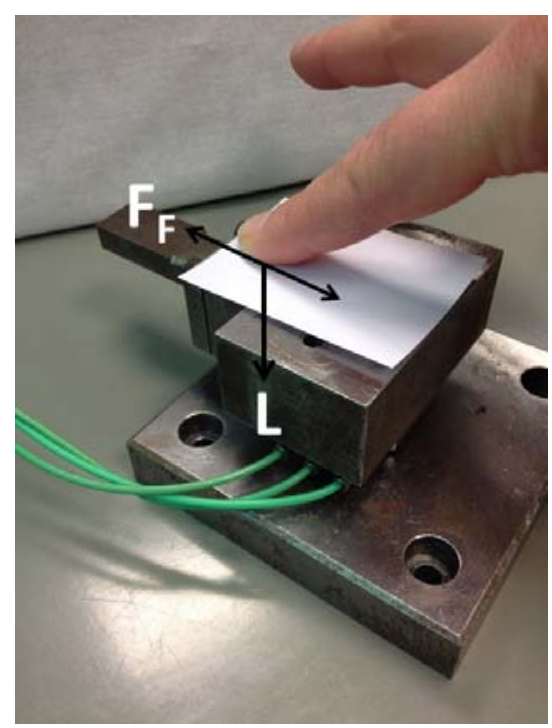

Figure 3. Finger friction measurement. The frictional force $\left(\mathrm{F}_{\mathrm{F}}\right)$ and loading force (L), or applied load, are recorded as the finger is moving over the paper surface in a standardized way.

Surface roughness. Physical surface roughness describes the amount of height differences on a surface. If the number of height deviations is large, the surface is rough and vice versa. The average surface roughness $\left(R_{a}\right)$ was measured with a NanoFocus $\mu$ Scan laser profilometer (NanoFocus AG, Germany). For each of the 21 paper stimuli, the $\mathrm{R}_{\mathrm{a}}$-value was averaged from six $150-\mathrm{mm}$ long line scans. $\mathrm{R}_{\mathrm{a}}$ is defined as the average absolute deviation of all points $x$ from the center line of the surface, that is

$$
R_{a}=\frac{1}{L} \int_{0}^{L}|z(x)| d x,
$$

where $L$ is the length of the profile line and $z$ is the surface height over the center line. Mathematically the center line is defined in such a way that the sum of the $z$ values is zero. 
Thermal conductivity. Thermal conductivity is a measure of a material's ability to conduct heat. Therefore, surfaces with a high thermal conductivity tend to feel cooler than surfaces with low thermal conductivity, since heat is then conducted faster from the skin. Thermal conductivity was measured with a HotDisk (HotDisc AB, Sweden), based on the Transient Plane Source (TPS) technique (Gustafsson, 1991). A current is applied to a thin film sensor with a radius of $14.67 \mathrm{~mm}$ (HotDisc 7280), which serves as both the heat source and thermometer. The thermal conductivity is obtained by monitoring the temperature increase, which is highly dependent on the thermal transport properties of the surrounding material, as a function of time. Stainless steel was used as a backing material. 


\section{Summary of studies}

The answers to the above mentioned questions will be discussed based on three research studies. Study I explores the psychophysical relationships between perceived coarseness and finger-friction and/or surface roughness. The purpose of this first study was in part, to attune haptically the friction measurement to perception as well as to research its importance to the perception of texture; and in part, to examine the feasibility to use the printing papers as stimulus material in the planned multidimensional scaling experiment in Study II. The main focus of this second experimental study was to research the dimensionality of fine textures, using the complex surfaces of printing paper combined with "natural" haptics. The MDS experiment in Study III was designed to explore the contribution of controlled and isolated surface properties to the haptic perception of fine textures, and to push the texture size down into the submicron scale and explore if it would be possible to discriminate textures of nano-scale.

\section{Stimulus and participants}

The three studies of this thesis use two distinctly different kinds of stimuli: complex (Study I and II) and simple (Study III) textures. Because of the effects of aging on texture perception, there was an exclusion criterion for participants older than 50 years. Study II and III only had female participants. This was in part a convenience decision and in part because we were not interested in gender differences. Different haptic procedures were selected for the three studies. The haptic procedure in Study I was selected to get a good fit with the measurements of friction. The haptic procedure in Study II aimed to allow for a more natural haptics for improved ecological validity, and also to activate more of the kinesthetic system. The Haptic procedure in Study III was aimed at being as close as possible to the one in Study II but because of the size and pattern of the surfaces, some restrictions had to be imposed. In all three studies, visual input was eliminated by every subject's use of blindfolds. Because of the length of the experiment, a decision was made not to introduce, additionally, pink noise. It was considered to be asking a bit too much of the participants to sit through the lengthy experiments with blindfolds and earphones. Table 2 shows a summary of the experimental designs of Studies I, II, and III. 
Table 2. An overview of the specifics of the three studies constituting the foundation of this thesis.

\begin{tabular}{|c|c|c|c|c|c|}
\hline Study & Stimuli & Participants & Method & Measurement & Haptics \\
\hline I & $\begin{array}{l}\text { Printing } \\
\text { paper } \\
\text { (complex) }\end{array}$ & $\begin{array}{l}10 \text { women } \\
\text { and } 15 \text { men, } \\
22-29 y\end{array}$ & $\begin{array}{l}\text { Magnitude } \\
\text { estimation }\end{array}$ & $\begin{array}{l}\text { Perceived: } \\
\text { Coarseness }\end{array}$ & $\begin{array}{l}\text { Dominant in- } \\
\text { dex finger, } \\
\text { restricted } \\
\text { movement }\end{array}$ \\
\hline \multirow[t]{2}{*}{ II } & $\begin{array}{l}\text { Printing } \\
\text { paper } \\
\text { (complex) }\end{array}$ & $\begin{array}{l}\text { Exp 1: } 10 \\
\text { women, } \\
21-47 \mathrm{y}\end{array}$ & $\begin{array}{l}\text { Magnitude } \\
\text { estimation }\end{array}$ & $\begin{array}{l}\text { Perceived: } \\
\text { Smoothness, } \\
\text { Coolness, Dry- } \\
\text { ness, Thickness; }\end{array}$ & $\begin{array}{l}\text { All fingers, } \\
\text { dominant hand, } \\
\text { free exploration }\end{array}$ \\
\hline & & $\begin{array}{l}\operatorname{Exp} 2: 20 \\
\text { women, } \\
20-37 \mathrm{y}\end{array}$ & $\begin{array}{l}\text { Multidimen- } \\
\text { sional scaling }\end{array}$ & Pairwise Smilarity & \\
\hline III & $\begin{array}{l}\text { Model } \\
\text { surfaces } \\
\text { (simple) }\end{array}$ & $\begin{array}{l}20 \text { women } \\
21-32 \text { y }\end{array}$ & $\begin{array}{l}\text { Multidimen- } \\
\text { sional scaling }\end{array}$ & Pairwise Similaity & $\begin{array}{l}\text { Index finger, } \\
\text { dominant hand } \\
\text { restricted } \\
\text { movement }\end{array}$ \\
\hline
\end{tabular}

\section{Study I}

\section{Background}

The physical properties of importance for this study were friction and surface roughness. Friction is known to be of limited importance for haptic perception of macrotexture (Lederman, 1974) but of increasing importance for finer textures (e.g. Wandersman, Candelier, Debrégeas, 2011; Tomlinson, Lewis \& Carre, 2009). Moreover, friction is mostly measured by probes, passive touch and/or synthetic skin (e.g. Derler, Schrade, \& Gerhardt, 2007; Derler, Gerhardt, Lenz, Bertaux \& Hadad, 2009; Liu, Yue, Cai, Chetwynd \& Smith, 2008). Roughness is a well researched property in haptic texture perception for macro as well as micro textures (Hollins \& Bensmaïa, 2007). The purpose of Study I was to research key properties (friction and roughness) and establishing ways of measuring them, examine their relevance to the coarseness perception of fine textures and also to pilot the stimuli materials for use in Study II. 


\section{Method}

\section{Participants}

Participants in Study I were 25 undergraduate students (10 women and 15 men) at the Royal Institute of Technology (KTH). The age range was 22-29 years. Participation in the experiment was mandatory for course credit. Two participants were excluded from the friction-measurement part and one participant was excluded from the perception-measurement part because of the time constraints set for the experimental session.

\section{Materials}

The stimuli for the experiments were eight different kinds of printing-papers (a subset of the total set used in Study II). Both finger-friction measures and perception measures were collected from the same subset of printing papers. A list of the stimuli and their specifications are presented in Table 3. There were two distinct categories of papers, coated and uncoated. For paper grades, the woodfree papers are made from chemical pulp rather than of mechanical pulp and supercalendering is a process to smoothen the uncoated papers to more resemble coated papers. As shown by the $R_{a}$-measures of surface roughness, the SC-A paper is smoothed to an amount that even surpasses the light weight coats and the machine finished coats.

For the friction measurements, the papers were cut into $4 \times 5 \mathrm{~cm}^{2}$ pieces to fit the finger friction measurement device, see Figure 3 for a picture of the device. The finger friction measurement procedure is presented in more detail in the Method section of the thesis. For the perception experiment the papers were presented in A4 standard format $(210 \times 297 \mathrm{~mm})$.

Table 3. The eight kinds of stimuli and their pre-measured characteristics. The uncoated papers are bolded.

\begin{tabular}{cccc}
\hline Sample name & Papergrade & $\begin{array}{c}\text { Grammage } \\
(\mathrm{g} / \mathrm{m} 2)\end{array}$ & $\mathrm{R}_{\mathrm{a}}$ Surface roughness $(\mathrm{lm})$ \\
\hline LWC 60 & Lightweight & 60 & 1.8 \\
MFC 60 & Machinefinished & 60 & 2.4 \\
News 45 & Newsprint & $\mathbf{4 5}$ & $\mathbf{4 . 0}$ \\
SC-A 60 & Supercalendered & $\mathbf{6 0}$ & $\mathbf{1 . 9}$ \\
WFC Gloss130 & Wood-free & 130 & 1.2 \\
WFC Gloss70 & Wood-free & 70 & 1.3 \\
WFC Matt70 & Wood-free & 70 & 1.7 \\
WFU 60 & Wood-free & $\mathbf{6 0}$ & $\mathbf{3 . 9}$ \\
\hline
\end{tabular}




\section{Procedure}

The method for scaling perceived coarseness was magnitude estimation; no modulus was set by the experimenter (see the "concepts and methods of measurements section" of this thesis for detailed information on the method of magnitude estimation). Each stimulus was presented 7 times for a total of $7 \times 8=56$ presentations, in a unique random order, for each participant. They were blindfolded and instructed to use the index finger of their preferred hand and to slide it up and down the length of the paper and to scale the perceived degree the coarseness of the paper, using their own scale of numbers. The participants were also instructed to try to keep constant load and speed while stroking the paper surface with their index finger. After the perception experiment the friction coefficient was measured and the participants were told to stroke the paper samples using the same index finger, using the same speed and load as in the perception experiment.

\section{Results and conclusions}

The results show a strong psychophysical relationship between Ra and Perceived coarseness $(r=0.85)$, see figure 4 . There was also a promising psychophysical, negative, relation between perceived coarseness and friction $(r$ $=0.67$ ). While there was variability between the participants' friction coefficients, the trend was very consistent across the participants. The conclusion from the analysis of the sliding modes was that a trained operator will produce consistent friction measures. Further, the participants performed well at scaling perceived coarseness, and the stimuli material is well categorized and very suitable material for perception experiments.

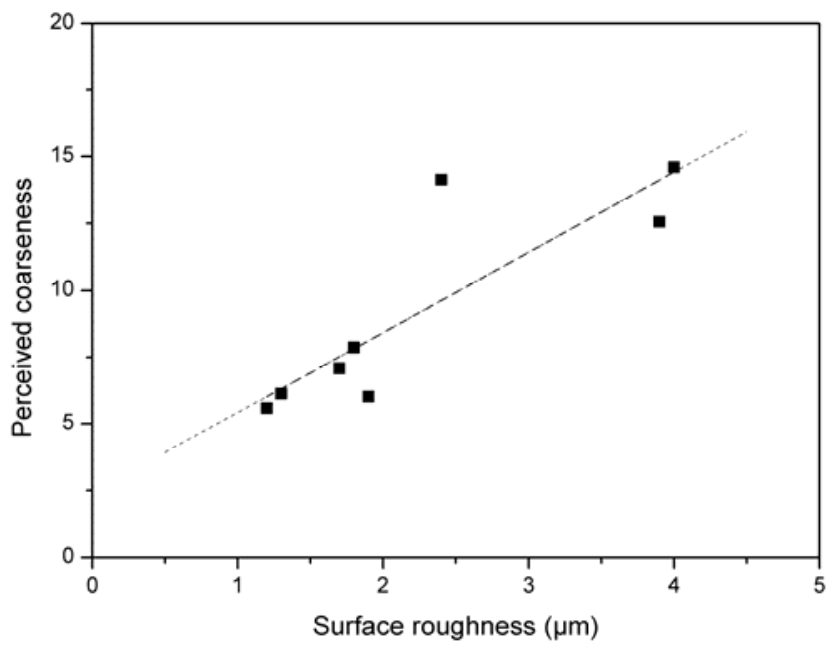

Figure 4. The relation between perceived coarseness and physical surface roughness. 


\section{Study II}

\section{Background}

Texture perception is a field of increasing interest. There are two distinct kinds of texture perception with different mechanisms, perception of macrotexture, which is perceived through the spatial system and microtexture, which is perceived through the vibratory system. This is referred to as the duplex theory of texture perception (Hollins \& Risner, 1998). The texture size that divides these two systems is $200 \mu \mathrm{m}$. There has been a considerable amount of research on the dimensionality of macrotexture (textures larger than $200 \mu \mathrm{m}$ ) and the most frequently reoccurring dimensionality with high interpretability is rough-smooth and hard-soft (Hollins, Bensmaïa, Karlof \& young, 2000; Picard, Dacremont, Valentin \& Giboreau, 2003; Bergmann Tiest $\&$ Kappers, 2005). Beyond these two dimensions there are often more dimensions found but these are harder to explain and replicate. Also, there seems to be individual differences in the use of the dimensions beyond the first two (Hollins, Bensmaïa, Karlof \& Young, 2000). For microtexture, however, there have been no perception experiments on dimensionality.

In this study, we attempt to fill the knowledge gap, by researching the dimensionality of microtextures and to find out how the space for the vibratory sense relates to the spaces for the spatial sense. Another goal is to research the contribution of physical properties and perceptual features to fine texture perception. The stimuli are printing papers with textures with element sizes between 2-10 $\mu \mathrm{m}$, that is, well below the $200 \mu \mathrm{m}$ limit for the spatial sense.

\section{Method}

\section{Participants}

In Experiment I, 10 women (mean: 30.2 \pm 8.9 , range: $21-47$ years old) participated, and in Experiment II 20 women (mean: 26.1 \pm 5.6 , range: $20-37$ years old) participated. All 30 participants were naïve to perception experiments and received monetary compensation for participation.

\section{Materials}

The stimulus materials were the same for both experiments, and were the complete set of printing papers that the stimulus material for Study I was derived from. The papers were presented in A4 standard size. Table 4 lists the stimuli and their specifications. 
Table 4 . The 21 printing paper stimuli and their measured physical properties.

\begin{tabular}{|c|c|c|c|c|}
\hline $\begin{array}{l}\text { Stimulus } \\
\text { incl. } \\
\text { weight (g) }\end{array}$ & $\begin{array}{l}\text { Finger fric- } \\
\text { tion } \\
\text { coefficient }\end{array}$ & $\begin{array}{l}\text { Surface rough- } \\
\text { ness } R_{a}(\mu \mathrm{m})\end{array}$ & $\begin{array}{l}\text { Thermal } \\
\text { conductivity } \\
\left(\mathrm{Wm}^{-1} \mathrm{~K}^{-1}\right)\end{array}$ & $\begin{array}{c}\text { Manufacturing character- } \\
\text { istics }\end{array}$ \\
\hline LWC 45 & $0.298 \pm 0.033$ & $1.96 \pm 0.05$ & 0.123 & Lightweight coated \\
\hline LWC 60 & $0.290 \pm 0.029$ & $1.75 \pm 0.04$ & 0.179 & Lightweight coated \\
\hline MFC 48 & $0.313 \pm 0.032$ & $2.55 \pm 0.04$ & 0.102 & Machine-finished coated \\
\hline MFC 60 & $0.309 \pm 0.032$ & $2.38 \pm 0.04$ & 0.106 & Machine-finished coated \\
\hline MWC 100 & $0.364 \pm 0.029$ & $1.28 \pm 0.03$ & 0.191 & Medium weight coated \\
\hline MWC 60 & $0.353 \pm 0.024$ & $1.54 \pm 0.03$ & 0.173 & Medium weight coated \\
\hline News 45 & $0.276 \pm 0.018$ & $4.03 \pm 0.07$ & 0.071 & Newsprint, uncoated \\
\hline SC-A 48 & $0.300 \pm 0.018$ & $2.00 \pm 0.05$ & 0.155 & $\begin{array}{l}\text { Supercalendered, virgin } \\
\text { fibres, uncoated }\end{array}$ \\
\hline SC-A 60 & $0.296 \pm 0.026$ & $1.91 \pm 0.03$ & 0.138 & $\begin{array}{l}\text { Supercalendered, virgin } \\
\text { fibres, uncoated }\end{array}$ \\
\hline SC-B 45 & $0.359 \pm 0.043$ & $2.12 \pm 0.04$ & 0.137 & $\begin{array}{l}\text { Supercalendered, recycled } \\
\text { fibers, uncoated }\end{array}$ \\
\hline SC-B 60 & $0.364 \pm 0.038$ & $2.20 \pm 0.04$ & 0.138 & $\begin{array}{l}\text { Supercalendered, recycled } \\
\text { fibers, uncoated }\end{array}$ \\
\hline $\begin{array}{l}\text { WFC- } \\
\text { Gloss } 100\end{array}$ & $0.476 \pm 0.077$ & $1.24 \pm 0.03$ & 0.242 & Woodfree coated, hf \\
\hline $\begin{array}{l}\text { WFC- } \\
\text { Gloss } 115\end{array}$ & $0.431 \pm 0.026$ & $1.23 \pm 0.03$ & 0.222 & Woodfree coated, hf \\
\hline $\begin{array}{l}\text { WFC- } \\
\text { Gloss } 130\end{array}$ & $0.386 \pm 0.040$ & $1.25 \pm 0.02$ & 0.210 & Woodfree coated, hf \\
\hline $\begin{array}{l}\text { WFC- } \\
\text { Gloss } 70\end{array}$ & $0.453 \pm 0.068$ & $1.34 \pm 0.03$ & 0.250 & Woodfree coated, hf \\
\hline $\begin{array}{l}\text { WFC-Matt } \\
100\end{array}$ & $0.423 \pm 0.071$ & $1.70 \pm 0.05$ & 0.174 & Woodfree coated, if \\
\hline $\begin{array}{l}\text { WFC-Matt } \\
70\end{array}$ & $0.411 \pm 0.087$ & $1.66 \pm 0.05$ & 0.189 & Woodfree coated, if \\
\hline $\begin{array}{l}\text { WFC-Silk } \\
115\end{array}$ & $0.381 \pm 0.027$ & $1.54 \pm 0.05$ & 0.196 & Woodfree coated, $\mathrm{mf}$ \\
\hline $\begin{array}{l}\text { WFC-Silk } \\
130\end{array}$ & $0.378 \pm 0.029$ & $1.59 \pm 0.04$ & 0.175 & Woodfree coated, $\mathrm{mf}$ \\
\hline WFU 100 & $0.277 \pm 0.019$ & $3.85 \pm 0.05$ & 0.110 & Woodfree uncoated \\
\hline WFU 60 & $0.284 \pm 0.020$ & $3.91 \pm 0.05$ & 0.098 & Woodfree uncoated \\
\hline
\end{tabular}

Footnote. For coating, $\mathrm{hf}=$ high finish, $\mathrm{mf}=$ medium finish, and $\mathrm{lf}=$ low finish. For information on properties, see methods. 
The papers were stored in a room with invariant temperature and humidity, and were moved to the experimental room 24 hours prior to each experimental session. To eliminate the risk of participants contaminating the paper surfaces by their hands (Skedung et al., 2010), each individual sheet of paper was discarded after each use. The blindfold used in the experimental sessions was a TEMPUR sleep mask.

\section{Procedure}

The weight (grammage) of the papers varied from 45 up to $130 \mathrm{~g} / \mathrm{m}^{2}$ and was determined using ISO 536:1995 standards. The physical measurements of finger friction, surface roughness and thermal conductivity are described in the concepts and methods of measurement section of this thesis.

In the first experiment, the perceptual attributes were measured with the method of magnitude estimation. The participants scaled the intensity of smoothness, coolness, dryness and thickness, one at the time with a short break in-between each session. Each participant received the stimuli in a unique random order.

In the second experiment, the participants scaled perceived similarity of the textures. The participants were blindfolded and completed the experiment individually. The participants were instructed to use all five fingers on their preferred hand and they were allowed to go back and forth between the stimuli within each pair before scaling the similarity.

\section{Results and conclusion}

The INDSCAL solution that best described the data was three-dimensional. The dimensionality was not clear-cut, but a scree-plot indicated a treedimensional solution and when comparing the $2 \mathrm{D}$ and $3 \mathrm{D}$ solutions, the $3 \mathrm{D}$ solution made more sense and increased the overall interpretability of the data. The interpretability of the output is a criterion, coupled with Stress, to choose dimensionality (Borg \& Groenen, 2010). To help explain the dimensionality of the textured surfaces, the four perceptual features, measured in Experiment 1 (smoothness, thickness, coolness, and dryness) and the four physical properties (surface roughness, weight, thermal conductivity, and finger friction) were fitted into the space in 2D planes. The dimensionality was interpreted as smooth-rough, thick-thin and distinct-indistinct; all three viewed as bipolar in the sense that they are inverse and overlapping, that is, they are not mutually exclusive (cf. Miller, 1991). Dimension 1 and Dimension 2 (smooth-rough, and thick-thin) correspond well to the reoccurring dimensions of macrotexture (Bergmann Tiest \& Kappers, 2006; Hollins, Bensmaïa, Karlof, \& Young, 2000; Picard, Dacremont, Valentin, \& Giboreau, 2003). The third dimension, distinct-indistinct, was not explainable 
through our physical or perceptual measures, but was explained as distinctindistinct because of the bipolar nature of the stimuli found to be high in Dimensions 3 (high roughness and high smoothness); this interpretation is not unlike the dimension found by Hollins, Bensmaïa, Karlof and Young (1998) and Gescheider, Bolanowski, Greenfield, and Brunette (2005), distinctiveness and clarity, respectively. I argue that this third dimension may be explained by spatial-sense discrimination of very fine textures, whereas previously the vibratory sense was assumed to be the sole contributor. It is possible that in the experimental context, where the large textures are around $10 \mu \mathrm{m}$ and the remaining textures are around 2-4 $\mu \mathrm{m}$, the larger textures are perceived as having 'macro-texture' in relation to the remaining stimuli.

\section{Study III}

\section{Background}

The interaction between finger and stimulus is complex, involving deformation of the finger from pressure and the vibratory information from movement (Childs \& Henson, 2007; Derler, Gerhardt, Lenz, Bertaux \& Hadad, 2010) as well as topographical and material characteristics (Tomlinson, Lewis \& Carre, 2009; Masen, 2011). Thus, when the finger slides over the material there will be both frictional forces and vibrations (Mate \& Carpick, 2011; Bensmaïa \& Hollins, 2003). These vibrations and frictional forces are in turn relayed through mechanoreceptors that are either slow adapting or in the case of fine texture perception, fast adapting (Johnson, 2001). A challenge to overcome when researching fine textures in a systematic way is the manufacturing of chemically identical surfaces, with elements spanning from the nanometer into the submillimeter size range, which are nonetheless large enough and robust enough to permit repeated interrogation with a finger. While there are known ways to manufacture nanostructured surfaces (Xia, Rogers, Paul \& Whitesides, 1999), these are often too small in size to use in haptic experiments. In this study a series of 16 wrinkled surfaces are manufactured with a size spanning from $300 \mathrm{~nm}$ to almost $100 \mu \mathrm{m}$ for the purpose of researching the specific contribution of pattern and friction changes to the haptic perception of fine textures. 


\section{Method}

\section{Participants}

Twenty women (21-32 years old) without prior experience of psychophysical experiments participated in this experiment. The participants were awarded theatre vouchers as compensation.

\section{Materials}

The stimulus materials for the experiment were model surfaces with a sinusoidal wave pattern, manufactured for the specific use as stimuli in this experiment (see Figure 2 for an illustration of a surface). A total of 18 different surfaces were used (50 $\mathrm{mm} \times 25 \mathrm{~mm}$ in size). The surfaces ranged from 300 $\mathrm{nm}$ to $80 \mu \mathrm{m}$ in wavelength and from $7 \mathrm{~nm}$ to $4.5 \mu \mathrm{m}$ in amplitude. The surfaces were gently cleaned with acetone and lint-free tissue between each use. The blind fold was a TEMPUR sleep mask.

Table 5. The 18 model surfaces and their measured characteristics.

\begin{tabular}{llllll}
\hline $\begin{array}{l}\text { Sur- } \\
\text { face } \\
(\mu \mathrm{m})\end{array}$ & $\begin{array}{l}\text { Wavelength } \\
(\mu \mathrm{m})\end{array}$ & $\begin{array}{l}\text { Amplitude } \\
(\mu \mathrm{m})\end{array}$ & $\begin{array}{l}\text { Aspect ratio } \\
\text { (amplitude/ } \\
\text { wavelength) }\end{array}$ & $\begin{array}{l}\text { Finger friction } \\
\text { coefficient }\end{array}$ & $\begin{array}{l}\mathrm{R}_{\mathrm{a}} \text { surface rough- } \\
\text { ness }(\mu \mathrm{m})\end{array}$ \\
\hline BS1 & - & - & - & $1.27 \pm 0.26$ & $0.001 \pm 0.000$ \\
BS2 & - & - & - & $1.41 \pm 0.68$ & $0.002 \pm 0.001$ \\
WS1 & $0.270 \pm 0.040$ & $0.007 \pm 0.001$ & 0.025 & $1.02 \pm 0.29$ & $0.003 \pm 0.001$ \\
WS2 & $0.760 \pm 0.050$ & $0.013 \pm 0.003$ & 0.017 & $1.21 \pm 0.31$ & $0.007 \pm 0.002$ \\
WS3 & $0.870 \pm 0.050$ & $0.022 \pm 0.005$ & 0.026 & $1.09 \pm 0.30$ & $0.012 \pm 0.003$ \\
WS4 & $17.5 \pm 1.0$ & $1.2 \pm 0.1$ & 0.067 & $0.52 \pm 0.21$ & $0.48 \pm 0.02$ \\
WS5 & $17.6 \pm 1.0$ & $1.2 \pm 0.1$ & 0.071 & $0.48 \pm 0.11$ & $0.58 \pm 0.08$ \\
WS6 & $20.5 \pm 0.9$ & $1.6 \pm 0.1$ & 0.080 & $0.31 \pm 0.07$ & $0.72 \pm 0.07$ \\
WS7 & $25.0 \pm 1.1$ & $3.1 \pm 0.3$ & 0.123 & $0.35 \pm 0.07$ & $1.64 \pm 0.23$ \\
WS8 & $25.1 \pm 1.2$ & $2.1 \pm 0.2$ & 0.082 & $0.29 \pm 0.08$ & $0.92 \pm 0.39$ \\
WS9 & $31.2 \pm 1.4$ & $2.4 \pm 0.3$ & 0.078 & $0.59 \pm 0.10$ & $1.38 \pm 0.15$ \\
WS10 & $34.0 \pm 2.4$ & $4.0 \pm 0.5$ & 0.119 & $0.52 \pm 0.10$ & $2.21 \pm 0.61$ \\
WS11 & $37.4 \pm 2.6$ & $4.5 \pm 0.4$ & 0.121 & $0.32 \pm 0.06$ & $2.56 \pm 0.26$ \\
WS12 & $39.9 \pm 2.9$ & $3.3 \pm 0.3$ & 0.081 & $0.54 \pm 0.12$ & $1.79 \pm 0.20$ \\
WS13 & $42.9 \pm 2.6$ & $3.6 \pm 0.3$ & 0.084 & $0.61 \pm 0.12$ & $2.09 \pm 0.18$ \\
WS14 & $46.5 \pm 2.6$ & $4.0 \pm 0.2$ & 0.085 & $0.67 \pm 0.17$ & $2.31 \pm 0.16$ \\
WS15 & $70.7 \pm 2.9$ & $1.9 \pm 0.1$ & 0.027 & $0.90 \pm 0.22$ & $1.06 \pm 0.06$ \\
WS16 & $90.0 \pm 4.3$ & $3.4 \pm 0.3$ & 0.038 & $0.82 \pm 0.16$ & $1.79 \pm 0.17$ \\
\hline
\end{tabular}

Footnote. The BS surfaces are the surfaces with unwrinkled film and WS are the surfaces with wrinkled film. 


\section{Procedure}

Before the experiment started, the participants washed and dried their hands. The participants were then given written and oral instructions. The task was to scale similarities between all possible pairs of the 18 surfaces, from $0 \%$ to $100 \%$ similar. The instruction was to stroke the surfaces with the index finger of their preferred hand. They were not allowed to move the finger sideways. Before the experiment started, a practice trial was given to both let the participant get accustomed to the scaling procedure and get a feel for the stimulus variations. The experiment was divided into 25 -min sessions, each session was followed by a five min break, and the second session was followed by a 20 min break. The temperature and relative humidity was measured to $20.5 \pm 1.3^{\circ} \mathrm{C}$ and $29 \pm 8 \%$, respectively.

\section{Results and conclusions}

A two-dimensional solution was chosen for this experiment. The stress values could be interpreted to suggest a three-dimensional solution, but after studying the output of both the two-dimensional and the three-dimensional solutions, the decision was made to select the two-dimensional option because of the fit to the physical measures. It seems that the third dimension represented scaling noise, and only served to make the space less interpretable. The two-dimensional solution exhibited a striking similarity to the plot of wavelength against friction, suggesting the perceptional dimensions are indeed associated with physical properties. Indeed, the plots of the scale values of Dimension 1 against friction and the scale values of Dimension 2 against wavelength did indeed yield very good fits. This means that these two physical properties explain the dimensionality of the INDSCAL solution very well. These results are presented as Figures 4 and 6 in the general discussion of this thesis.

Given the relationship between friction and surface roughness (Derler \& Gerhardt, 2012), and the texture of the surfaces, it is not surprising that the INDSCAL solution assumed such a close approximation to the physical plot. It is, however, very noteworthy that the participants could discriminate such extremely similar surfaces as well as they did. These results also confirm that friction is indeed very important to the perception of microtextures.

The final, and perhaps most remarkable, finding from Study III is that two of the nanosurfaces did not fall into the general pattern of the other surfaces in the INDSCAL solution. The smallest wrinkled surface with $300 \mathrm{~nm}$ wavelength and a $7 \mathrm{~nm}$ amplitude grouped with the surfaces covered with an unwrinkled film, suggesting the participants could not discriminate it from the two 'blanks'. The two larger nanosurfaces though, the smallest of which had a wavelength of $760 \mathrm{~nm}$ and amplitude of $13 \mathrm{~nm}$, grouped together and out- 
side of the general pattern of the remaining textures. This suggests that the participants could discriminate them from the blanks, but not by the means of friction and wavelength. This is both thrilling and confusing. An amplitude of only $13 \mathrm{~nm}$ is enough to separate a wrinkled surface from a flat surface, but what is the perceptual mechanism? 


\section{General discussion}

This general discussion will address the main findings of Studies I, II, and III, as well as discuss the implications for texture perception, haptics, and tactile dimensionality.

\section{Main findings}

To cement the foundation of this thesis there was a need to establish a proper method of measurement for friction, evaluate the $R_{a}$ measure for surface roughness and to determine the relevant perceptual features and physical properties of the stimulus materials in psychophysical experiments. In Study I, a measuring method for human finger friction was established and the representativeness of a finger for measuring friction is determined. Much attention and research have been dedicated to measure friction with artificial probes designed to mimic human fingers or to develop measurement models with fingers (e.g. Derler, Gerhardt, Lenz, Bertaux, \& Hadad, 2009; Tomlinson, Lewis, \& Carre, 2009; Masen, 2011). The benefits of such probes are obvious in its standardization and quality of measurement. However, in Study I, the aim was to measure the friction with the aid of human participants to better describe the perceptions in terms of haptic texture perception. The experimental results yield a measuring model based on the first three sampling cycles out of 15 conducted, because there is a change in friction that happens after three cycles. To better fit the natural human-texture interaction, these first three cycles were isolated and used for the measurement of friction (indeed, it is a rare occasion in a persons life when you decide to continuously rub a surface 4-15 times to decide on the potential friction of the surface). To relate both the friction and $R_{a}$ measures to perceptual features of stimulus surfaces, a separate perception experiment was also conducted on the printing papers. The results of Study I yielded good psychophysical relationships between perceived coarseness and both the $\mathrm{R}_{\mathrm{a}}$ and the friction measures of the paper surfaces.

Katz (1925) hypothesised that texture perception was actually a composition of two senses, the spatial sense for coarse textures and the vibratory sense for fine textures. This theory of haptic perception is called the Duplex Theory. In more recent times this Duplex Theory has been refined, supported and 
polished. Hollins \& Risner (2000) found that the vibratory sense made little contribution to the perception of textures larger than $200 \mu \mathrm{m}$. One of the goals of this thesis was to further examine this theory and evaluate the contribution of these senses in the realm of textures below $200 \mu \mathrm{m}$ to see if a similar isolation of sensory information happened. As shown in Study II, the MDS solution of textures below $10 \mu \mathrm{m}$ corresponded well to earlier research on course textures and surfaces, indicating a similar perceptual system. What was further found in this study was that the coarser textures (around $8 \mu \mathrm{m}$ ) differed from the general pattern of the finer textures (around $2 \mu \mathrm{m}$ ). This separation in perception is likely due to recognition of the actual texture and not a product of the vibratory separation that explains the remaining textures. These findings indicate that there is indeed a contribution of spatial information even at this fine scale. This finding both support and further the Duplex Theory. The presence of two perceptual systems is evident. However, contrary to the Duplex Theory which suggests that these fine textures should be perceived through the vibratory sense; in the present thesis I argue that the stimulus context reshapes the definition of fine and coarse textures, perceptually. Meaning that the $8 \mu \mathrm{m}$ textures, that would fall into the category of fine textures and thus vibratory-sense perception, were perceived as coarse, in the context of the experimental setting, and were thus perceived through spatial information. This is in accordance with the research that shows vibrations can be relayed through probes to convey spatial information (Klatzky \& Lederman, 1999; Yoshioka et al, 2007; Delhaye, Hayward, Lefevre \& Thonnard, 2012). While there is no doubt that vibration is necessary to perceive anything at all at these fine textures, both senses seem to still play an important role in microtexture perception, and the Duplex Theory should be considered in relative rather than absolute terms, or perhaps that the duplex part is a perception phenomenon and not just a receptor phenomenon.

The Duplex Theory seems to explain, through vibratory and spatial information, haptic perception of fine and coarse textures. Research suggests that below $1 \mu \mathrm{m}$ the ability to discriminate is lost. For example, Johansson and LaMotte (1983) showed that $1 \mu \mathrm{m}$ is the limit for texture perception. However, just because the ability to detect single asperities, or acknowledge patterns, diminishes around $1 \mu \mathrm{m}$, does that mean that patterns in the submicron range are not detectable? This question was answered in Study III, where the textures ranged from $80 \mu \mathrm{m}$ down to $300 \mathrm{~nm}$, sporting a pattern-amplitude of just $7 \mathrm{~nm}$ as the finest texture. What was found in this experiment was that the participants were indeed unable to separate the finest texture $(300 \mathrm{~nm}$ wrinkles with $7 \mathrm{~nm}$ amplitude) from the unwrinkled surfaces (same material but unwrinkled). However, they were able to discriminate the $760 \mathrm{~nm}$ wrinkles, $13 \mathrm{~nm}$ amplitude surfaces from the unwrinkled surfaces. While $760 \mathrm{~nm}$ is fairly close to the $1 \mu \mathrm{m}$ limit found in previous research, the amplitude of 
the waves on the surfaces in Study III was $13 \mathrm{~nm}$. For the $800 \mathrm{~nm}$ waves to be detected, the amplitude of $13 \mathrm{~nm}$ must have been large enough for detection. It is highly unlikely that the participants felt the actual pattern at these nano textures, yet the perception of similarity differed all the same. As seen in Figure 5 the detection was not based on friction. So, if the discrimination is not based on friction, vibration or spatial information, what was then used to discriminate these fine textures? The most likely scenarios would be perceptual cues to surface stickiness, or to warm or cold surface temperature, but unfortunately this thesis was unable to answer this particular question. However, this makes for an excellent research area to follow up on.

\section{Surface textures}

This thesis also aimed to research the haptic perception of fine textures, defined here as surfaces with elements of less than $200 \mu \mathrm{m}$ in size. To better understand the mechanisms of the perception at this small scale, two different kinds of textures were scrutinized.

1. Complex textures. The complex textures were the printing papers used in Study I and Study II. These textures are formed by haphazard 'flexible' patterns as fibres are crossed.

2. Simple textures. The simple textures were the model surfaces with 'rigid' wrinkles used in Study III. These textures were created to systematically varying in wavelength and amplitude, keeping all other variables constant.

It is clear from the results of Study I and Study II that the complex fine textures behave much in the same way as the coarse textures used in earlier research (e.g. Bergmann Tiest \& Kappers, 2006) and the perceptual space relates closely to those found in earlier research. The results from Study III showed that rather than taking on the general MDS pattern and dimensionality of the complex surfaces, participants successfully organized the surfaces according to the principal by which they were manufactured, reflected by wavelength and friction. The 2D MDS pattern for simple surfaces and the plots of friction $(\mu)$ vs. wavelength are shown in Figure 5. 


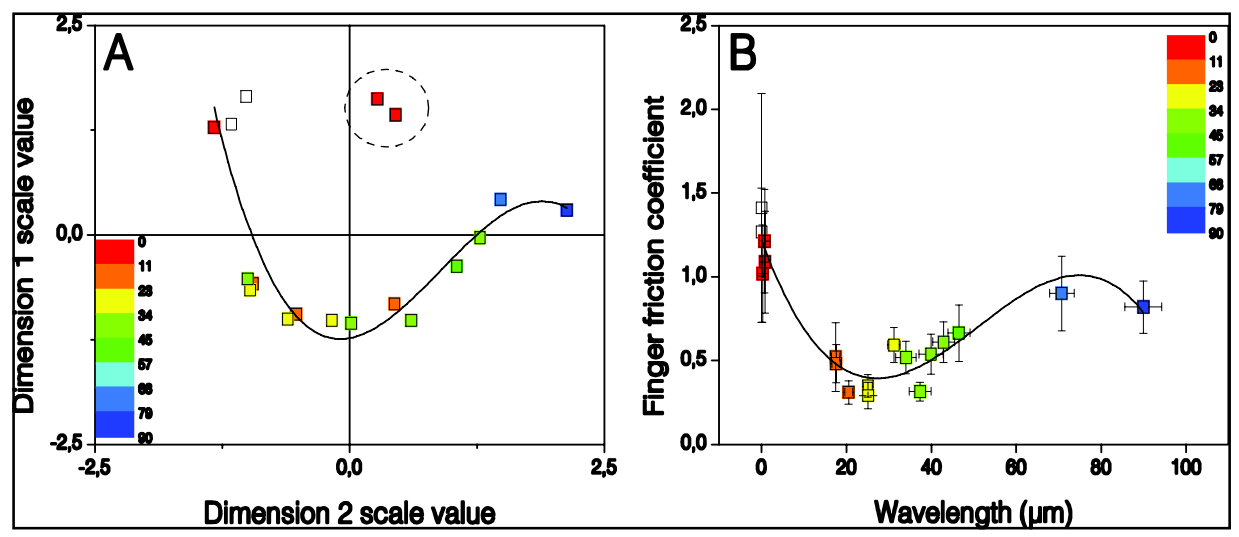

Figure 5. Perception and physical measures of wrinkled surfaces. (A) Twodimensional (tactile) space of perceived similarities of the 18 surfaces. The closer the points in this tactile map, the more the surfaces are perceived as similar. (B) Finger friction versus wrinkle wavelength. There are clear similarities between the point distributions in (A) and (B) suggesting that participants may use friction and wrinkle wavelength as cues in scaling similarities among the surfaces. As a guide to the eye a third order polynomial is fitted to the empirical data. The surface with smallest stimulus pattern (WS1, $\lambda=270 \mathrm{~nm}$ ) was not distinguished from the two unwrinkled surfaces, whereas the $\lambda=760 \mathrm{~nm}$ and $\lambda=870 \mathrm{~nm}$ surfaces were. (dashed ring in A) The amplitudes of these latter surfaces are $13 \mathrm{~nm}$ and $22 \mathrm{~nm}$ respectively. An arbitrary color scale has been generated where blue represents the surface of largest wavelength and red that of shortest wavelength. The unfilled points correspond to the unwrinkled reference surfaces.

The conclusions drawn from these findings regarding fine textures are that fine textures can be considered in much the same way as their more coarsely textured counterparts, even though there are supposedly two different perceptual systems involved. In the coarse texture perception it is mainly the spatial sense that is relied upon for discrimination while on the fine textures we rely mostly on the vibratory sense. For the simple textures, the similarity scaling captures the systematically changed variable formidably, which could mean that other structures in the same size range $(0-80 \mu \mathrm{m})$ can be researched systematically as well. Complex textures are more akin to the textures one would expect to meet in real life situation and the modelling of them seems to be transferable between materials and size ranges. The simple fine-textures on the other hand yielded a very good interpretation of the manipulated variable and seem like a very viable way to study the effect of single properties on a more complex system. 


\section{Dimensionality}

One of the goals of this thesis was to map the dimensionality of fine surface texture. While Study I made it clear that the printing papers were suitable as scalable microtextures, more sophisticated experiments were needed for researching the dimensionality. In Study II, an extended set of the printing papers from Study I were scaled and mapped with INDSCAL software, the resulting 3D image is shown in Figure 6. The space was interpreted through the results of Experiment 1 and the complementary physical measurements. Figure 8 shows Dimensions 1 vs 2 and 1 vs 3 with the vectors of the physical and perception measurements fitted into the two plains. The general pattern of the 3D space for printing papers corresponds well with the perceptual spaces of objects, larger textures, and across-materials spaces demonstrated in previous research (Bergmann Tiest \& Kappers, 2006; Gescheider, Bolanowski, Greenfield, \& Brunette, 2005; Hollins, Bensmaïa, Karlof, \& Young, 2000; Yoshioka, Craig, Beck, \& Hsiao, 2007). One of the goals of this thesis was to map the dimensionality of fine surface texture. While Study I made it clear that the printing papers were suitable as scalable microtextures, more sophisticated experiments were needed for researching the dimensionality. In Study II, an extended set of the printing papers from Study I were scaled and mapped with INDSCAL software, the resulting 3D image is shown in Figure 6 . The space was interpreted through the results of Experiment 1 and the complementary physical measurements. The general pattern of the 3D space for printing papers corresponds well with the perceptual spaces of objects, larger textures, and across-materials spaces delivered in previous research. 


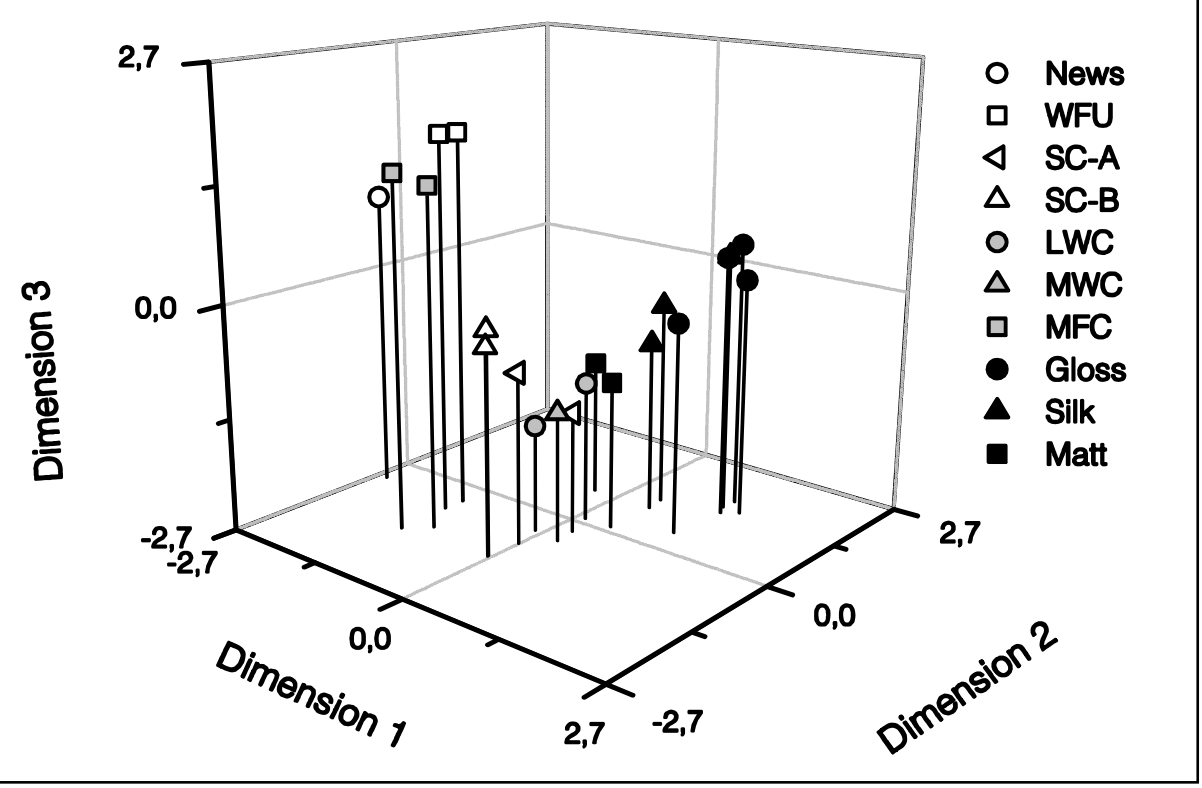

Figure 6. The 3D INDSCAL representation of perceived dissimilarities of 21 printing papers in Study II.

The interpretation of the dimensionality also corresponds well with the interpretations of the dimensions of coarser textures with Dimension 1 as a rough-smooth dimension, Dimension 2 as thick-thin dimension and Dimension 3 as a distinct-indistinct dimension. The interpretation of Dimension 1 is a straightforward interpretation and the fact that roughness and smoothness is a present dimension is hardly surprising, since this is the case for most surfaces. The interpretation of Dimension 2 is also not surprising; the thickness of the printing papers contributed to surface feel in a similar way as hardness does on other materials. The reason I chose thickness over hardness was because of our stimulus materials, for which it would be awkward to consider printing paper surfaces as hard or soft. Thickness, however, made more sense in the context of our stimuli and it would roughly translate into an equivalent perceptual feature. Dimension 3 for the complex fine texture surfaces was harder to interpret, and there were no physical or perceptual measures that captured this third dimension. The most reasonable interpretation for this dimension was distinct-indistinct. The rationale behind this interpretation is that the textures that were high in Dimension 3 were opposites in all the measured perceptual features and physical properties. The only thing they shared were that they possessed very high or very low quantities of the measured attributes, that is, the printing papers that were highest in Dimension 3 had by far the roughest surfaces; this is shown visually in Fig- 
ure 7. The papers that were high in Dimension 3, but opposite in Dimension 1 and 2 were the thickest and most heavily coated (gloss). The common ground for these papers was that they were distinctly different from the remaining papers in their dominating characteristics and were therefore more recognizable.
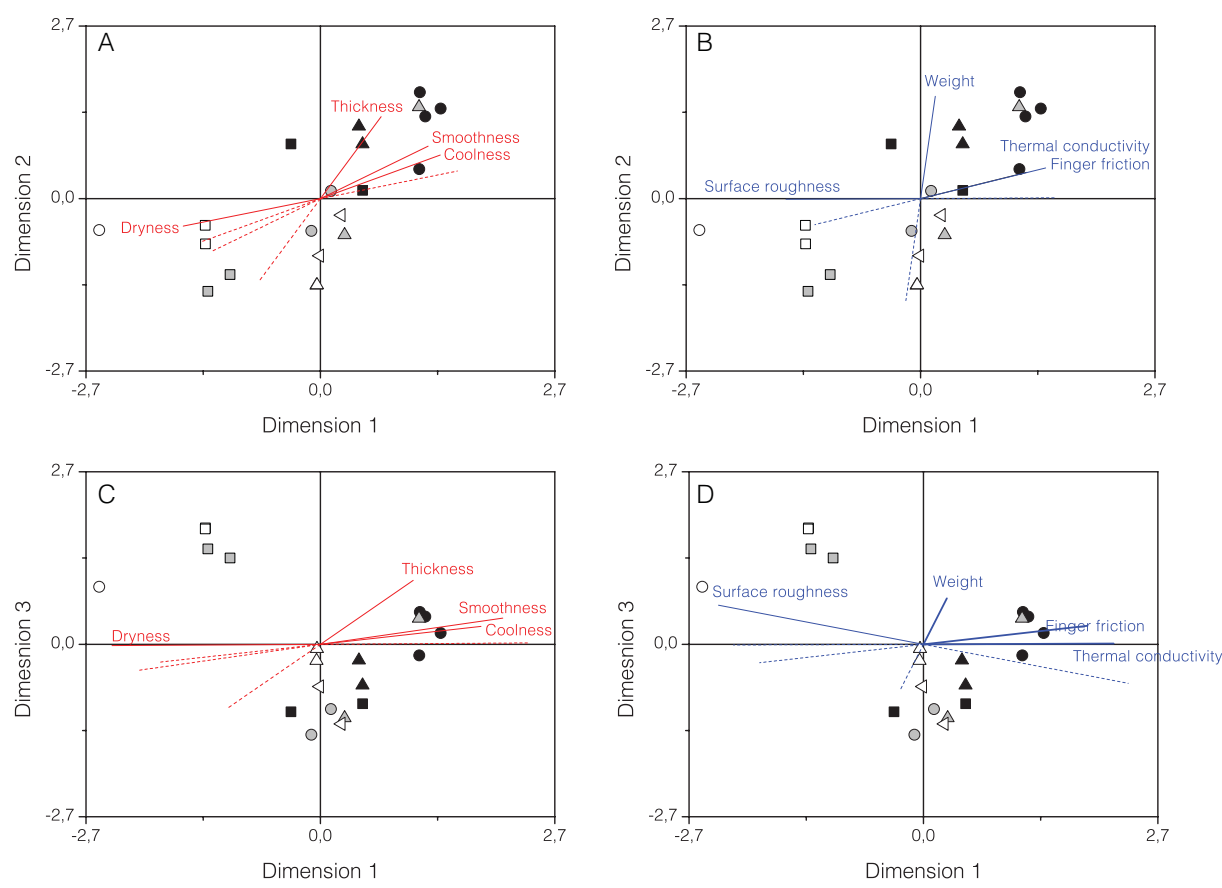

Figure 7. The 3D multidimensional space of Figure 6 displayed in two-dimensional planes with Dimension 1 as X-axes; Dimension 2 plots at the top and Dimension 3 plots at the bottom. In the two left diagrams, $\mathrm{A}$ and $\mathrm{C}$, the four perceptual features are presented as vectors; and in the two right diagrams, B and D, the four physical properties are the vectors. For all vectors, the higher quantities are illustrated as full lines and the lower quantities as dotted lines. 

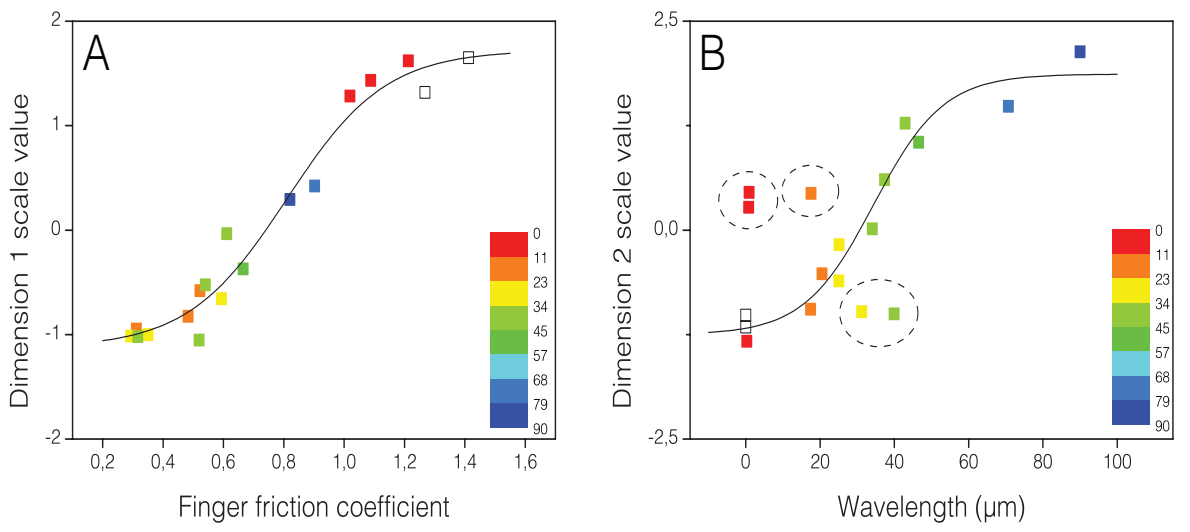

Figure 8. MDS coordinates from perception experiment versus physical data. (A) Dimension 1 scale value versus finger friction coefficient (B), Dimension 2 scale value versus wrinkle wavelength. The fitted sigmoidal dose response functions are a guide for the eye. In B, the stimuli within the circles are excluded from the function fitting. These functions imply that the slope regime in the middle is where humans are most sensitive. The two asymptotes indicate sensor saturation. The color mapping (the same as in the other figures) is based on pattern wavelength from low wavelength (red) to larger wavelengths (blue).

The simple 'rigid' textures in Study III gave a very different solution to the dimensionality of the complex textures. The participants in Study III virtually recreated the function of friction and wavelength as can be seen in Figure 4. The two dimensions are further explained in Figure 8 where the scale values of Dimension 1 and Dimension 2 are plotted against friction and wavelength, respectively. There are several interesting points to this particular psychophysical space, one being that the solution fits the data surprisingly well even though it was burdened with fairly high stress values. This indicates that the participants indeed could scale microtexture in a very comprehensive way and gives support for the INDSCAL solution of Study II that also had high stress values. The other interesting point that arises from the INDSCAL solution is the two largest nano-scale stimuli separated from the blank surfaces whereas the smallest nano-scale surface did not. This, in-turn, indicates that surfaces with a sinusoidal wave pattern of $760 \mathrm{~nm}$ were indeed discriminable from the blank surfaces, where as the $300 \mathrm{~nm}$ surfaces were not. The most striking observation here is that the amplitude of this $760 \mathrm{~nm}$ surface was $13 \mathrm{~nm}$. 


\section{Haptics}

Study I, II, and III of this thesis all had a different approach to haptic exploration. Since the main purpose of Study I was to relate the friction to the perception of coarseness, the haptics in the perception experiment emulated the friction measurement. This haptic method was controlled in space but not in time, the participants were not asked to scale coarseness during a certain time frame. This liberty in time restraint was kept throughout all three studies, but the restriction in space varied. In Study II the haptic design was meant to give some ecological validity to the experimental results. Instead of, as standard practice in most tactile experiments, using the index finger and slide it in a lateral motion over a surface, or for that matter letting the surface slide against the index finger in the name of experimental control. A decision was made to allow the participants to freely explore the surface for as long as they wished before scaling the similarity or the unidimensional features of the stimuli. By doing this, the participants got input from all fingers as well as the kinesthetic information of the moving arm, together representing a more natural way to explore a paper surface, and a chance to gather more perceptual information than involved in surface roughness. As it turned out, the roughness, not unexpectedly, came out as the strongest dimension. However, the physical roughness was not linear to its reverse perceived smoothness and indeed it showed saturation at the roughest textures, see Figure 9. This was not reflected in the INDSCAL space, where the rougher textures were clearly and distinctly separated from the remaining textures, especially in Dimension 3. It is also noteworthy from Study I, where the haptics were more restricted, that the perceived coarseness seems linear to $\mathrm{R}_{\mathrm{a}}$ as opposed to the corresponding measures in Study II. Of course it is dubious to draw conclusions, because of the restricted stimulus set of Study I. The haptic procedure of Study III had to be constrained in part because of the size of the stimuli and in part because of the wave pattern that was meant to be research. 

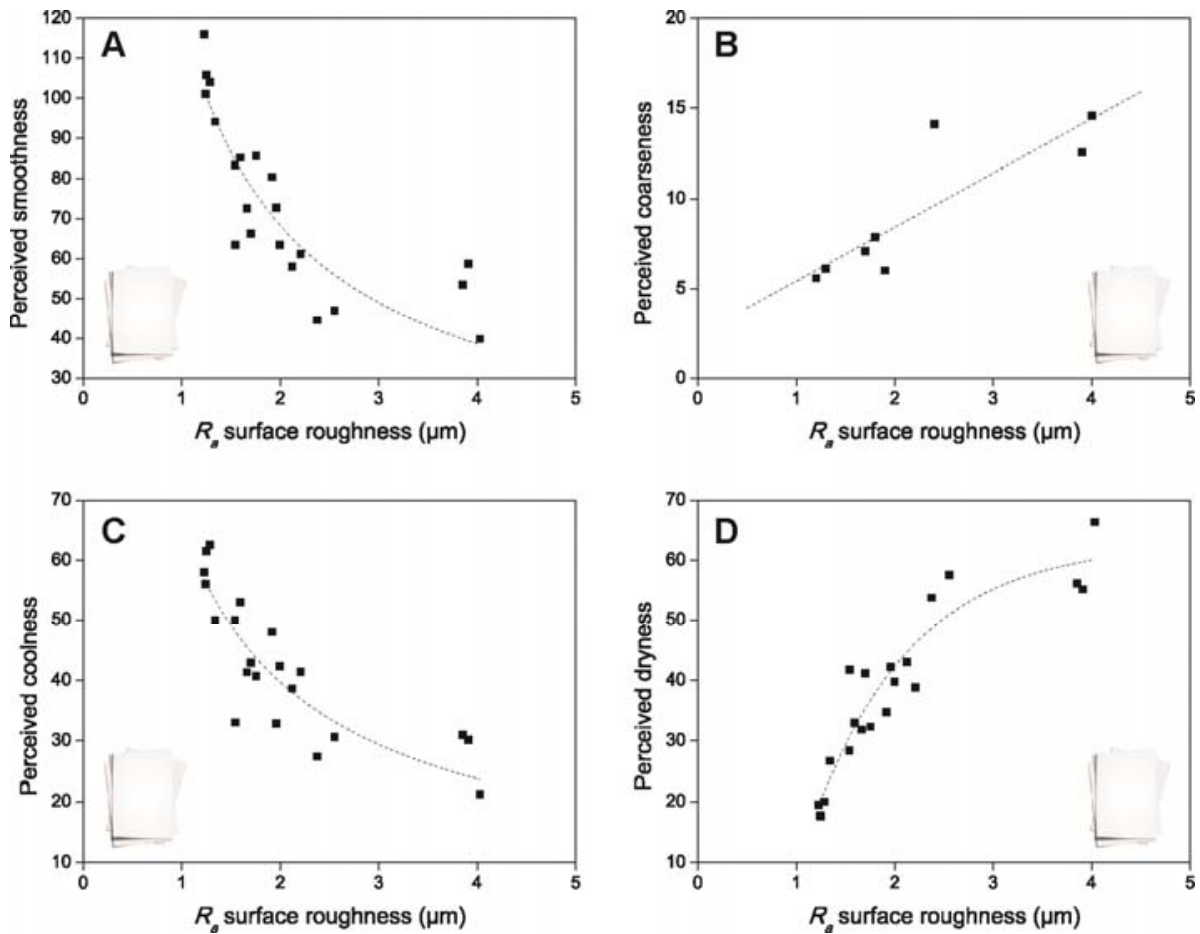

Figure 9. Physical roughness plotted vs. perceived (A) smoothness, (B) coarseness, (C) coolness, and (D) dryness.

Perhaps the most interesting part about the haptics is the third dimension in Study II. In the experiment, participants were allowed to explore the surface freely and the resulting dimension was explained as distinctiveness, a dimension that is also discussed by, for example Hollins et al (1998) and Gescheider, Bolanowski, Greenfield and Brunette (2005). Though Hollins et al (1998) argue that this occurs because some materials are not dimensional; the results from Study II lead me to believe that this is not the case. Figure 5 shows a trend that even smoothened papers with recycled fibres (SC-B) start to approach the rough papers that are high in Dimension 3. I speculate that the rough papers were perceived spatially whereas the remaining papers are perceived through vibrations. This might be considered a bit controversial since the current research claims that the vibratory system is responsible for the texture perception at this texture scale. However, with free exploration with all fingers of the hand over a large surface, it seems quite possible that multiple vibrations could be detected by the Pacinian channels and are perceived as spatial variation, but through movement. Since the two-point threshold for vibration stimuli (on the sole of the foot) is $1.2 \mu \mathrm{m}$ (Kowalzik, Hermann, Biedermann, \& Peiper, 1996), and the detection level of a single 
asperity is $1 \mu \mathrm{m}$ it seems quite possible that the rougher textures were indeed perceived as spatially different from the remaining surfaces.

\section{Methodological issues}

In any experimental study there are methodological issues to address. The following section will address three issues: The Stress values of the MDS solutions (badness-of-fit), stimuli, and participants.

\section{Stress}

The multidimensional scaling experiments in Study II and Study III are deliberately set up to only encompass microtextures, complex and simple respectively. What is evident from the results is that the stress values are rather high. Though this might be a problem, it is unavoidable if one intends to research the dimensionality of fine textures. It is noteworthy that the stress levels were very similar for both Study II and Study III.

The difficulty level of scaling similarity of minute texture differences is obviously high and as such invites more error. Seeing how error is a known source for inflated stress, it is no wonder the stress values are much higher than for example in multidimensional scaling experiments of macro-textures or objects. I am sure the reader can imagine the difference in difficulty of scaling similarity between two paper grades and between a rock and a metal pipe. However, high stress due to error is not necessarily a problem in multidimensional scaling, if the error is randomly distributed, i.e. equal amount of over and under estimations. On the contrary, as in any psychological experiment, the inclusion of more data points will yield more reliable data; but this is not reflected in the stress. The inclusion of more data points that contain error will result in higher stress, although for all intent and purposes, the inclusion of these points is to generate a more accurate measure (Borg \& Groenen, 2010). The group data for the test-retest measurements show that the error does indeed seem to be randomly distributed. Given that the error is high, and that also the test-retest correlation is high, it seems very reasonable to assume that at a group level the error is indeed randomly distributed, and as such a likely explanation for the high stress.

The second criterion for assessing the fit of the model is to examine its fit to the actual data. In Study III, the stimulus materials were simple surfaces with controlled structures. In this experiment the INDSCAL representation of the data was a very close approximation of the manipulated wavelength and the resulting finger-friction, see Figure 5. The close fit to the physical measure- 
ments suggests that the participants did indeed manage to scale the similarities of these fine textures in a most credible way.

\section{Stimuli}

There were two different kinds of stimuli materials in the three studies. The model surfaces used in Study III were robust and made it through hundreds of uses before starting to yield, which unfortunately meant we could only use the first 10 participants for the main analysis. The general pattern was intact even with the worn surfaces, but the differences were reduced. While it is definitely an issue that the number of participants got reduced to 10 this is still a reasonable number of participants for a similarity experiment of this magnitude. This problem would have been wonderful to avoid, but time constraints and budget limited the possible amount of manufactured surfaces to two sets of 18 usable surfaces. The printing-papers used for Study I and Study II on the other hand, did not suffer from the same problem as the model surfaces. For these two, studies there were enough stimulus material to use a fresh sheet of paper for each trial.

\section{Participants}

The participants for Study II and Study III were all women, which can raise the question of how well the results can be generalized to men. It was a conscious decision to only include women based in part on convenience and in part because of possible gender differences. I had difficulty recruiting men to previous studies and I was not interested in gender differences. I found no evidence that women and men should have different texture perception, if anything there might be a sensitivity difference that would be applicable in Study III for the nano-scale stimuli. But if there is a gender difference in sensitivity I would have needed twice as many participants to keep each group at the desired 20. Instead of risking having only a few male participants (who might differ in sensitivity) contra a large group of women, the decision was made to restrict participation to women.

\section{Implications and further research}

The results of this thesis can hopefully help to better understand the mechanisms of fine texture perception. Immediate and relative impact would be for the manufacture of consumer products such as hair products, textiles and particularly printing papers, where the spaces can be used to predict the impact of varying surface treatments. The prospect of nanocoatings is also exciting, both for further research and for application on haptic devices and other products. 
There are several key issues to explore further. It would be good to replicate the findings of Study III by using a larger set of surfaces and with a larger amount of stimuli of each kind to ensure the surfaces will hold for the full length of the experiment. A same-different threshold experiment on the same type for surfaces would also be desirable. Another interesting rout would be to pursue the influence of nanocoatings on haptic devices, such as smart phones.

\section{Final thoughts on texture perception}

In concordance with previous research all three studies of this theses support the importance of friction and roughness to texture perception, both for simple and complex textures and for restricted and unrestricted haptics. There does, however, seem to be more to texture perception than these two reoccurring properties. While the finger-friction measurements developed in Study I worked well for explaining dimensionality in the sinusoidal textured surfaces and $R_{a}$ being a reliable measurement across all three studies of this thesis. $R_{a}$ also has a good fit to the perception measurements. Neither of these managed to capture the differentiation of the nano-scale surfaces in Study III. No obvious explanation was reached as to what exactly separated the nano surfaces but as far as speculation goes, the degree of stickiness could be a contributor. It does; however, seem that the perception of fine textures goes a bit further than the roughness perception, even more so when one considers the difference in material properties that goes beyond the geometry of the surface. The MDS solution of Study II differed greatly from the MDS solution of Study III and it seems likely that both the haptic procedure and the material properties contribute to the perception of the complex nature of the paper surfaces. The importance of haptic exploration in microtexture perception can also be researched further by varying the modes (active/passive) and mediation (probes) on surfaces like the ones used in the studies of this thesis. 


\section{Conclusions}

The main conclusions of this thesis are:

- It is possible to use multidimensional scaling on a set of microtexture of the same material and the dimensionality is very similar to that of macrotexture perception that is believed to be activated by a different sensory system.

- Micro and macro-textures are context dependent in a way that reaches beyond the element sizes of the textured surfaces. Even micro texture can be perceived spatially through vibrations in haptic search.

- Roughness and friction are indeed key components of perception of fine texture but at the submicron scale it seems that discrimination is based on neither of these.

- There may be a kinesthetic component to haptic perception of fine texture.

- And finally, the human hand is capable of discriminating between blank surfaces and nano-wrinkled rigid surfaces with amplitudes as small as $13 \mathrm{~nm}$. 


\section{References}

Bensmaïa, S. J., \& Hollins, M. (2003). The vibrations of texture. Somatosensory \& Motor Research, 20, 33-43.

Bensmaïa, S. J., \& Hollins, M. (2005). Pacinian representations of fine surface texture. Perception \& Psychophysics, 67, 842-854.

Bensmaïa, S. J., Hollins, M., \& Yau, J. (2005). Vibrotactile intensity and frequency information in the Pacinian system: A psychophysical model. Perception \& Psychophysics, 67, 828-841.

Bergmann Tiest, W. M., \& Kappers, A. M. L. (2006). Analysis of haptic perception of materials by multidimensional scaling and physical measurements of roughness and compressibility. Acta Psychologica, $121,1-20$.

Bergmann Tiest, W. M., \& Kappers, A. M. L. (2007). Haptic and visual perception of roughness. Acta Psychologica, 124, 177-189.

Bergmann Tiest, W. M., \& Kappers, A. M. L. (2009). Tactile perception of thermal diffusivity. Attention, Perception, \& Psychophysics, 71, 481-489.

Bolanowski, S. J., Verrillo, R. T., \& McGlone, F. P. (2004). Passive, active, and intra-active (self) touch. Behavioural Brain Research, 148, 4145.

Borg, I., \& Groenen, P. J. F. (2010). Modern Multidimensional Scaling: Theory and Applications ( $2^{\text {nd }}$ ed.). New York: Springer Science+Business Media Inc.

Brisben, A. J., Hsiao, S. S., \& Johnson, K. O. (1999). Detection of vibration transmitted through an object grasped in the hand. Journal of Neurophysiology, 81, 1548-1558.

Carroll, J. D., \& Chang, J. J. (1970). Analysis of individual differences in multidimensional scaling via an n-way generalization of "EckartYoung" decomposition. Psychometrika, 35, 283-319.

Childs, T. H. C., \& Henson, B. (2007). Human tactile perception of screenprinted surfaces: self-report and contact mechanics experiments. Journal of Engineering Tribology, 221, 421-441.

Cussler, E. L., Zlotnick, S. J., \& Shaw, M. C. (1977). Texture perceived with the fingers. Perception \& Psychophysics, 21, 504-512.

Delhaye, B., Hayward, V., Lefevre, P., \& Thonnard, J-L. (2012). Textureinduced vibrations in the forearm during tactile exploration. 
Frontiers in Behavioural Neuroscience. 6, doi:

10.3389/fnbeh.2012.00037

Derler, S., \& Gerhardt, L-C. (2012). Tribology of skin: Review and analysis of experimental results for the friction coefficient of human skin. Tribology Letters, 45, 1-27.

Derler, S, Schrade, U., \& Gerhardt, L-C. (2007). Tribology of human skin and mechanical skin equivilents in contact with textiles. Wear, 263, 1112-1116.

Derler, S, Gerhardt, L-C., Lenz, A,, Bertaux, E., \& Hadad, M. (2009). Friction of human skin against smooth and rough glass as a function of the constant pressure. Tribology International, 42, 1565-1574.

Gandevia, S. C. (1996). Kinesthesia: Roles of affrentsignals and motor commands. In L.B. Rowel \& J.T Shepherd (Eds.), Handbook of Physiology: Section 12. Exersice: Regulation and Integration of Multiple Systems (pp. 128-172). New York: Oxford University Press.

Geldard, F. A., \& Sherrick, C. E. (1972). "The Cutaneous "Rabbit": A Perceptual Illusion". Science, 178, 178-179.

Gescheider, G. A. (1976). Evidence in support of the duplex theory of mechanoreception. Sensory Processes, 1(1), 68-76.

Gescheider, G. A. (1997). Psychophysics: The Fundamentals. Mahwah, NJ: Lawrence Erlbaum.

Gescheider, G. A., Bolanowski, S. J., Greenfield, T. C., \& Brunette, K. E. (2005). Perception of the tactile texture of raised-dot patterns: A multidimensional analysis. Somatosensory and Motor Research, 22, 127-140.

Gescheider, G. A., Sklar, B. F., Van Doren, C. L., \& Verrillo, R. T. (1985). Vibrotactile forward masking: Psychophysical evidence for a triplex theory of cutaneous mechanoreception. Journal of the Acoustic Society of America, 78, 534-543.

Gescheider, G. A., Verrillo, R. T., Capraro, A. J., \& Hamer, R. D. (1977). Enhancement of vibrotactile sensation magnitude and predictions from the duplex model of mechanoreception. Sensory Processes, 1, 187-203.

Gescheider, G. A., Edwards, R. R., Lackner, E. A., Bolanowski, S. J., \& Verrillo, R. T. (1996). The effects of aging on informationprocessing channels in the sense of touch: III. Differential sensitivity to changes in stimulus intensity. Somatosensory and Motor Research, 13, 73-80.

Goldreich, D. (2007). A bayesian perceptual model replicates the cutaneous rabbit and other spatiotemporal illusions. PLoS ONE, 2, e333. doi:10.1371/journal.pone.0000333

Goldreich, D., \& Kanics, I.M. (2003). Tactile acuity is enhanced in blindness. Journal of Neuroscience, 23, 3439-3445. 
Green, B. G. (1990). Effects of thermal, mechanical, and chemical stimulation on the perception of oral irritation. In B.G. Green, J.R. Mason \& M. R. Kare (Eds.), Chemical senses. Vol. 2: Irritation. New York: Marcel Dekker Inc., pp. 171-195.

Grunwald, M. (Ed.). (2008). Human Haptic Perception: Basics and Applications. Basel: Birkhäuser Verlag.

Guest, S., \& Spence, C. (2003). Tactile dominance in speeded discrimination of textures. Experimental Brain Research, 150, 201-207

Gustafsson, S. E. (1991). Transient plane source techniques for thermalconductivity and thermal-diffusivity measurements of solid materials. Review of Scientific Instruments, 62, 797-804.

Halata, Z., Grim, M., \& Baumann, K. I. (2003). Freidrich Sigmund Merkel and his "Merkel cell", morphology, development, and physiology: Review and new results. The Anatomical Recor: Advances in Integrative Anatomy and Evolutionary Biology, 271, 225-239.

Ho, H.-N., \& Jones, L. A. (2006). Contribution of thermal cues to material discrimination and localization. Perception \& Psychophysics, 68, 119-129.

Hollins, M., \& Bensmaïa, S. J. (2007). The coding of roughness. Canadian Journal of Experimental Psychology, 61, 184-195.

Hollins, M., Bensmaïa, S., Karlof, K., \& Young, F. (2000). Individual differences in perceptual space for tactile textures: Evidence from multidimensional scaling. Perception \& Psychophysics, 62, 1534-1544.

Hollins, M., Faldowski, R., Rao, S., \& Young, F. (1993). Perceptual dimensions of tactile surface texture: A multidimensional scaling analysis. Perception \& Psychophysics, 54, 697-705.

Hollins, M., \& Risner, S. R. (2000). Evidence for the duplex theory on tactile texture perception. Perception \& Psychophysics, 62, 695-705.

Johansson, R. S., \& LaMotte, R. H. (1983). Tactile detection thresholds for a single asperity on an otherwise smooth surface. Somatosensory Research, 1, 21-31.

Johansson, R. S., Landström, U., \& Lundström, R. (1982). Responses of mechanoreceptive afferent units in the glabrous skin of the human hand to sinusoidal skin displacements. Brain Research, 244, 17-25.

Johnson, K. O. (2001). The roles and functions of cutaneous mechanoreceptors. Curr. Opin. Neurobiol, 11, 455-461.

Johnson, K. O., \& Lamb, G. D. (1981). Neural mechanisms of spatial tactile discrimination: Neural patterns evoked by Braille-like dot patterns in the monkey. Journal of Physiology, 310, 117-144.

Katz, D. (1989). The World of Touch (L.E. Kruger transl.). Hillsdale, NJ: Erlbaum. [original work published 1925].

Klatzky, R. L., \& Lederman, S. J. (1999). Tactile roughness perception with a rigid link interposed between skin and surface. Perception \& Psychophysics, 61, 591-607. 
Klatzky, R. L., Lederman, S. J., \& Metzger, V. A. (1985). Identifying objects by touch: An "expert system". Perception \& Psychophysics, 37, 299-302.

Kowalzik, R., Hermann, B., Biedermann, H., \& Peiper, U. (1996). Two point discrimination of vibratory perception on the sole of the human foot. Foot Ankle International, 17, 629-634.

Lakatos, S., \& Marks L. E. (1999). Haptic form perception: Relative salience of local and global features. Perception \& Psychophysics, 61, 895908.

Lederman, S. J. (1974). Tactile roughness of grooved surfaces: The touching process and effects of macro- and microsurface structure. Perception and Psychophysics, 16, 385-395.

Lederman, S. J., \& Klatzky, R. L. (1987). Hand movements: A window into haptic object recognition. Cognitive Psychology, 19, 342-368.

Lederman, S. J., \& Klatzky, R. L. (2004). Haptic identification of common objects: effects of constraining the manual exploration process. Perception \& Psychophysics, 66, 618-628.

Lederman, S. J., \& Klatzky, R. L. (2009). Haptic perception: A tutorial. Attention, Perception, \& Psychophysics, 71, 1439-1459.

Lederman, S. J., \& Taylor, M. M. (1972). Fingertip force, surface geometry, and the perception of roughness by active touch. Perception \& Psychophysics, 12, 401-408.

Libouton, X., Barbier, O., Berger, Y., Plaghki, L., \& Thonnard, J. (2012). Tactile roughness discrimination of the finger pad relies primarily on vibration sensitive afferents not necessarily located in the hand. Behavioural Brain Research, 229, 273-279.

Liu, X., Yue, Z., Cai, Z., Chetwynd, D. G., \& Smith, S. T. (2008). Quantifying touch-feel perception: tribological aspects. Measurement Science \& Technology, 19, 084007

Louw, S., Kappers, A. M. L., \& Koenderink, E. J. (2000). Haptic detection thresholds of Gaussian profiles over the whole range of spatial scales. Experimental Brain Research, 132, 369-374.

Lövenberg, J., \& Johansson, R. S. (1984). Regional differences and interindividual variability in sensitivity to vibration in the glabrous skin of the human hand. Brain Research, 301, 65-72.

Masen, M. A. (2011). A system based experimental approach to tactile friction. Journal of the Mechanical Behavior of Biomedical Materials, 4, 1620-1626.

Mate, M. C., \& Carpick, R. W. (2011). A sense for touch. Nature, 480, 189190

Miller, G. R. (1991). The Science of Words. NY: Scientific American Library. 
Miyaoka, T., Mano, T., \& Ohka, M. (1999). Mechanisms of fine-surfacetexture discrimination in human tactile sensation. Journal of the Acoustical Society of America, 105, 2485- 2492.

Miyazaki, M., Hirashima, M., \& Nozaki, D. (2010). "The "cutaneous rabbit" hopping out of the body.". The Journal of Neuroscience: the Official Journal of the Society for Neuroscience, 30, 1856-60.

Picard, D., Dacremont, C., Valentin, D., \& Giboreau, A. (2003). Perceptual dimensions of tactile textures. Acta Psychologica, 114, 165-184.

Scheibert, J., Leurent, S., Prevost, A., \& Debregeas, G. (2009). The role of fingerprints in the coding of tactile information probed with a biometric sensor. Science, 323, 1503-1506.

Schiffman, S. S., Reynolds, M. L., \& Young, F. (1981). Introduction to Multidimensional Scaling: Theory, Methods, and Applications. NY: Academic Press.

Skedung, L., Danerlöv, K., Olofsson, U., Aikala, M., Niemi, K., Kettle, J., \& Rutland, M. W. (2010). Finger friction measurements on coated and uncoated printing papers. Tribology Letters, 37, 389-399.

Skedung, L., Danerlöv, K., Olofsson, U., Johanesson, C. M., Aikala, M., Kettle, J., Arvidsson, M., Berglund, B., \& Rutland, M. W. (2011). Tactile perception: Finger friction, surface roughness and perceived coarseness. Tribology International, 44, 505-512.

Srinivasan, M. A., Whitehouse, J. M., \& LaMotte, R. H. (1990). Tactile detection of slip: surface microgeometry and peripheral neural codes. Journal of Neurophysiology, 63, 1323-1332.

Stevens, J. C., \& Patterson, M. Q. (1995). Dimensions of spatial acuity in the touch sense: Changes over the life span. Somatosensory \& Motor Research, 12, 29-47.

Stevens, S. S. (1975). Psychophysics: Introduction to its Perceptual, Neural, and Social Prospects. New York: Wiley.

Stevens, S. S. (1957). On the psychphysical law. Psychological Review, 64, 153-181.

Taylor, M. M., \& Lederman, S. J. (1975). Tactile roughness of grooved surfaces: A model and the effect of friction. Perception \& Psychophysics, 17, 23-36.

Tomlinson, S. E., Lewis, R., \& Carre, M. J. (2009). The effect of normal force and roughness on friction in human finger contact. Wear, 267, $1311-1318$

Vallbo, A. B., \& Johansson, R. S. (1984). Properties of cutaneous mechanoreceptors in the human hand related to touch sensation. Human Neurobiology, 3, 3-14.

Wandersman, E., Candelier, R., Debregeas, G., \& Prevost, A. (2011). Texture-induced modulations of friction force: The fingerprint effect. Physical Review Letters, 107, 164301 
Weber, E. H. (1851). Die Lehre vom Tastinn und Gemeingefühl - auf Versuche Gegründet. Verlag Friedrich Vieweg und Sohn, Braunschweig: translated (1978) The sense of touch. Academic Press, London.

Xia, Y. N., Rogers, J. A., Paul, K. E., \& Whitesides, G. M (1999). Unconventional methods for fabricating and patterning nanostructures. Chemical Review, 99, 1823-1848.

Yoshioka, T., Bensmaïa, S. J., Craig, J. C., \& Hsiao, S. S. (2007). Texture perception through direct and indirect touch: An analysis of perceptual space for tactile textures in two modes of exploration. Somatosensory and Motor Research, 24, 53-70.

Yoshioka, T., Craig, J. C., Beck, G. C., \& Hsiao, S. S. (2011). Perceptual constancy of texture roughness in the tactile system. Journal of Neuroscience, 31, 17603-17611.

Yoshida, M. (1968). Dimensions of tactual impressions (1), (2). Japanese Psychological Research, 10, 123-137, 157-173. 